\title{
LOS ACTORES EN EL DERECHO INTERNACIONAL PRIVADO DEL SIGLO XXI
}

\author{
Ruben Santos \\ Belandro
}

\section{Resumo}

El fenómeno de la globalización ha trastocado seriamente la imagen del derecho internacional privado tradicional basada en las ideas de reparto, de localización, de territorio y de soberanía de los Estados, todos temas a los que se intentó dar un tratamiento adecuado en la región, sobre el final del s. XIX y mediados del s. XX. Hoy las fronteras nacionales -base para el razonamiento de un derecho internacional privado sobre premisas savignianas- resultan muchas veces intrascendentes. El ser humano se ha vuelto ubicuo, en el sentido de que su pensamiento, voluntad y acción, pueden superar la región donde nació y vive, para incidir en cualquier rincón del mundo, pactando por ejemplo, contratos por medios electrónicos. Es ineludible tomar en consideración estas circunstancias, para salvarnos del riesgo de promocionar un Derecho inadecuado o ineficaz.

Corresponde entonces, volver a examinar los viejos criterios sobre los que se ha basado nuestra disciplina. Cabe pensar que en algunas áreas importantes la transformación que ha sufrido el Estado ha llevado a que deje ser el eje de la sociedad internacional. Es necesario asimismo razonar sobre el hecho de que también se han transformado los patrones de poder en las relaciones internacionales, en cuanto a su naturaleza y en cuanto a las formas de operar en el nuevo modelo de sociedad. El poder y la autoridad siguen siendo temas centrales en nuestro ámbito, pero varían los actores. Igualmente aparecen nuevas formas de gestionar ciertos temas, que la globalización ha llevado a todo el orbe.

Para un mejor tratamiento dividiremos el tema en tres partes: la primera nos permitirá observar la evolución que han experimentado los Estados en su estructura y en el aspecto gestionario; la segunda estará dedicada a precisar el concepto y las características de la sociedad internacional tal como se presentan al día de hoy; y la última, estará referida al individuo, centro de referencia del derecho internacional privado. En la Sección 2, examinaremos la variedad metodológica presente en el derecho internacional privado. Y en la Sección 3 constataremos que el problema no reside en el pluralismo metodológico sino en la búsqueda de una adecuada coordinación entre diferentes sistemas jurídicos. Coordinación que puede y debe

\footnotetext{
${ }^{1}$ Profesor Agregado de Derecho Internacional Privado y Profesor Agregado de Derecho Extranjero y Comparado en la Facultad de Derecho de la Universidad Mayor de la República, Uruguay. E-mail: epder@fder.edu.uy
} 
realizarse sobre el plano normativo, institucional y procesal recurriendo a una importante variedad de herramientas.

Palabras clave: Globalización, Derecho Internacional Privado, Transformación del Estado, Sociedad Internacional, Individuo.

\section{INTRODUCCIÓN}

El fenómeno de la globalización ha trastocado seriamente la imagen del derecho internacional privado tradicional basada en las ideas de reparto, de localización, de territorio y de soberanía de los Estados, todos temas a los que se intentó dar un tratamiento adecuado en la región, sobre el final del s. XIX y mediados del s. XX. Hoy las fronteras nacionales -base para el razonamiento de un derecho internacional privado sobre premisas savignianas- resultan muchas veces intrascendentes. El ser humano se ha vuelto ubicuo, en el sentido de que su pensamiento, voluntad y acción, pueden superar la región donde nació y vive, para incidir en cualquier rincón del mundo, pactando por ejemplo, contratos por medios electrónicos. Es ineludible tomar en consideración estas circunstancias, para salvarnos del riesgo de promocionar un Derecho inadecuado o ineficaz.

Corresponde entonces, volver a examinar los viejos criterios sobre los que se ha basado nuestra disciplina. Cabe pensar que en algunas áreas importantes la transformación que ha sufrido el Estado ha llevado a que deje ser el eje de la sociedad internacional. Es necesario asimismo razonar sobre el hecho de que también se han transformado los patrones de poder en las relaciones internacionales, en cuanto a su naturaleza y en cuanto a las formas de operar en el nuevo modelo de sociedad. El poder y la autoridad siguen siendo temas centrales en nuestro ámbito, pero varían los actores. Igualmente aparecen nuevas formas de gestionar ciertos temas, que la globalización ha llevado a todo el orbe. ${ }^{2}$

Para un mejor tratamiento dividiremos el tema en tres partes: la primera nos permitirá observar la evolución que han experimentado los Estados en su estructura y en el aspecto gestionario; la segunda estará dedicada a precisar el concepto y las

\footnotetext{
${ }^{2}$ Ibáñez Muñoz, Joseph. Poder y autoridad en las relaciones internacionales: el control del comercio electrónico en Internet. Universitat Pompeu Fabra. Barcelona. 2002. 
características de la sociedad internacional tal como se presentan al día de hoy; y la última, estará referida al individuo, centro de referencia del derecho internacional privado. En la Sección 2, examinaremos la variedad metodológica presente en el derecho internacional privado. Y en la Sección 3 constataremos que el problema no reside en el pluralismo metodológico sino en la búsqueda de una adecuada coordinación entre diferentes sistemas jurídicos. Coordinación que puede y debe realizarse sobre el plano normativo, institucional y procesal recurriendo a una importante variedad de herramientas.

\section{LOS ESTADOS CAMINO HACIA LA VERSATILIDAD}

El Estado, en el cenit de su evolución, practicó una apropiación (o expropiación) de las fuentes de producción jurídica en la escena internacional, y se presentó como la única voz legítima para resolver los casos originados en el derecho internacional privado a fines del s. XIX. Todo el poder se concentraba en el Estado soberano; fuera de él, nos encontrábamos en el ámbito del no-Derecho, de lo no jurídico -del vacío o de la irrelevancia en una palabra- entorno que no merecía ser analizado ni regulado. ${ }^{3}$

La estrategia desarrollada no era algo nuevo; el propio Estado Nación ya lo había puesto en práctica para afirmarse en el orden interno, derogando las costumbres locales en beneficio de un Código único; centralizando el ejercicio del poder político dentro del territorio; unificando la administración; sometiendo la jurisprudencia con la finalidad de que adoptara una actitud uniforme, mecánica y silogística, de respeto y veneración a la ley. Sin duda que desde el s. XIX hasta mediados del s. XX la época marcó el apogeo de los Estados Naciones en cuanto éstos aparentaban ser sólidos, fuertes, absolutistas en lo interno y, pretendidamente absolutistas en el ámbito internacional, difundiendo "por sí o a través de otras instituciones sociales, ideología de aceptación del orden políticosocial, obteniendo consenso, interiorización de la regimentación por las personas, y hegemonía”. ${ }^{4}$ Los Estados eran los actores centrales. ${ }^{5}$ Fue también la época del

\footnotetext{
${ }^{3}$ Carbonnier, Jean. Flexible Droit. Textes pour une sociologie du droit sans rigueur. Paris. 1983.

4 "Suele atenderse poco a la función estatal de generar ideología de aceptación, fundamental para reducir la visibilidad de la actividad coercitiva”. Capella, Juan Ramón. Fruta prohibida. Una aproximación histórico-teorética al estudio del Derecho y del Estado. Madrid. 2001. 3a. Edición. p. 47. ${ }^{5}$ Vivir en sociedad significaba vivir estatalmente. "La concepción del Estado-nación soberano fue formulada (enfatizando las formas, los límites y los fundamentos del poder político-jurídico), a partir vol.08, $n^{\circ}$. 01, Rio de Janeiro, 2015. pp. 299-349 301
} 
esplendor del método de conflicto de leyes, el cual adquirió el calificativo de método "clásico" (en cuanto estaba destinado a perdurar como modelo a través del tiempo). Significó asimismo, la exclusión de la voluntad de los individuos en la tarea de determinar el Derecho aplicable al caso heterogéneo, la que fue sustituida por una armadura permanente de normas legales. ${ }^{6}$ Supervisaba cada paso que los sujetos daban o podían dar y castigaba decididamente a cualquiera que se pasara de la raya, lo cual provocaba una sobrecarga de seguridad. ${ }^{7}$

No obstante su pretendido clasicismo -y como consecuencia de este calificativo una idea de invulnerabilidad subyacente - las críticas a esta forma de razonar y de regular los problemas privados de los particulares en el ámbito internacional fueron creciendo -lenta pero persistentemente, hasta hacer eclosión en la década de los años 30 del s. XX. Según el calificativo de Prosper Weil, los Estados eran alvéolos territoriales en yuxtaposición, donde la función espacial -propia de la regla de conflicto en este casosepara, divide y opone. ${ }^{8}$ Como consecuencia de estas críticas la regla de conflicto se redireccionó, encaminándose a partir de ese momento hacia la versatilidad.

\section{HACIA UN NECESARIO REEXAMEN DE LA NOCIONES DE LA SOBERANÍA Y DEL PODER}

El origen de la doctrina de la soberanía estatal se remonta a la formulación que hiciera Jean Bodin en su obra De Republica en 1576, quien concibió la soberanía como el atributo característico del Estado. ${ }^{9}$ En el s. XIX, Uruguay como el resto de los países de

del presupuesto de una comunidad nacional de destino. Es decir, de una comunidad formada por individuos libres, una comunidad que se gobierna a sí misma con libertad absoluta para determinar su propio rumbo, y en consecuencia, establecer su propio futuro. Sin embargo, este presupuesto ha sido cuestionado tanto por la naturaleza como por el alcance de las diversas interconexiones entre organizaciones multiplicadas por el proceso de globalización, lo que impide a los Estados nacionales - por medio de sus gobiernos- programar con exclusividad las acciones, las decisiones, los planes y las políticas públicas. En una situación límite, por consiguiente, 'la sociedad de individuos' acabaría siendo sustituida por una 'una sociedad de organizaciones', en la medida en que cada ciudadano terminaría encuadrando su vida económica, política, cultural, e incluso familiar, en la(s) organización(es) a la(s) que pertenece." Faría, José Eduardo. El Derecho en la economía globalizada. Madrid. 200o. p. 149. (Énfasis del autor).

${ }^{6}$ Faría, José Eduardo. El Derecho Op. cit. p. 36.

${ }^{7}$ Bauman, Zygmunt. La sociedad sitiada. Argentina. 2004. p. 80 y 81.

${ }^{8}$ Weil, Prosper. Le droit International en quête de son identité. Cours général de droit international public. Recueil des Cours. 1992. 237. VI. p. 35 y 36.

${ }^{9}$ Krabbe, H. L'idée moderne de l'État. Recueil des Cours. 1926. 13. III. p. 513. 
América, se encontró abocado a la tarea de la afirmación de su propia personalidad jurídica mediante el establecimiento de relaciones seguras con los demás Estados en todos los ámbitos posibles y, fortalecer el imperio de su orden jurídico en lo interno.

Por ese motivo, para elaborar su sistema plasmado en su proyecto de Código de Derecho Internacional Privado redactado en 1888 Gonzalo Ramírez recurrió a uno de los atributos del Estado: nuestra disciplina debía ser una ciencia que tuviera por cometido específico resolver un conflicto de soberanías. La afirmación de este concepto en el ámbito exterior fue importante porque habilitó a considerar que todos los Estados tenían el mismo grado de soberanía -como decía Carrillo Salcedo, que "más allá del Estado no hay ninguna autoridad humana establecida"10 - y por tanto, que todos eran iguales en la medida de su personalidad, lo que permitió a un pequeño país como Uruguay, acceder a un trato de igual a igual con el resto de los integrantes de la comunidad internacional. Uruguay propició hasta el límite de lo posible esta característica, fomentando negociaciones con los demás países del continente, con el objetivo de redactar normas comunes de derecho internacional privado, y su protagonismo permaneció por mucho tiempo.

El concepto de soberanía también resultó importante en lo interior, ya que habilitó a cada Estado a tener el monopolio de la custodia del interés general sobre su territorio, capaz él solo de definirlo y de uniformar reglas de juego y establecer condiciones a todos los actores bajo su jurisdicción. Decíamos en otra oportunidad que "el Estado fue el elemento constituyente de lo social, fue el agente de la organización de la nación, de la puesta en forma de la sociedad, el proveedor de la identidad colectiva. $\mathrm{Su}$ papel fue decisivo, porque en Uruguay la formación del Estado precedió cronológicamente a la nación, otorgándole coherencia e identidad a la sociedad, al suministrarle referencias comunes que no existían en su punto de partida"."

A partir de la vigencia del modelo westfaliano de Estados Naciones, el territorio se configuró no sólo como un espacio político sino también, como un espacio económico. Entre los s. XVIII y XIX las fronteras de los Estados coincidieron con las fronteras de los mercados y se produjo una nacionalización del derecho del comercio

\footnotetext{
${ }^{10}$ Carrillo Salcedo, Juan-Antonio. Droit international et souveraineté des États. Cours general de droit international public. Recueil des Cours. 1996. 257. p. 60.

${ }^{11}$ Santos Belandro, Ruben. Las normas de aplicación inmediata en la doctrina y el derecho positivo. Revista de la Facultad de Derecho. Julio-Diciembre de 1995. No. 8. p. 75. 
internacional. La globalización económica, sin embargo, vino a implantar un proceso diferente: el surgimiento de una economía que en algunos aspectos podía considerarse como global o mundial, lo cual condujo a la configuración en muchos sectores y actividades, de mercados transnacionales, regionales, globales o mundiales. Estos mercados ya no son mercados nacionales con una delimitación geográfica coincidente con la de las fronteras territoriales de los Estados. De este modo se fue quebrando la articulación histórica entre mercados nacionales y territorialidad estatal, poniendo de manifiesto la existencia diferenciada de diversos niveles o redes socio-espaciales de interacción social: las locales o sub-estatales; las estatales propiamente dichas, enmarcadas en la territorialidad de los Estados; las interestatales, correspondiente a la sociedad internacional de Estados; las transnacionales, que trascienden esas fronteras y son autónomas; y las globales, que abarcan a todo el planeta. ${ }^{12}{ }^{13}$ Como afirma Éric Loquin, "el desafío del s. XXI será el de administrar un espacio transnacional, donde las relaciones humanas se establecerán con una dimensión espacial que niegue la división en órdenes jurídicos estatales autónomos. Ante todo, esos espacios transnacionales son mercados económicos que se afirman como globales, como universales. Las legislaciones estatales resultan impotentes para aprehender relaciones que no tienen otra base territorial que el conjunto del planeta y que la ley de un Estado en particular, no puede tener legitimidad para regularla". ${ }^{14}$ ¿Habrá llegado el momento de transformar al derecho internacional en un derecho material? ¿Quintín Alfonsín redivivus? ¿Habrá llegado a tanto la lucidez de nuestro Maestro, que con sólo 27 años en 1938 vaticinó este cambio sobre el cual, salvo él, nadie creía? "En el estado actual de nuestra ciencia decía en el año 1955, que todavía tropezamos con esta alternativa, pero que el progreso científico encamina sus pasos hacia la solución privatista". ${ }^{15}$

En la actualidad se argumenta la irrelevancia creciente de la soberanía como principio fundamental del sistema de Estados Naciones. ${ }^{16}$ Sin embargo, debemos comenzar por plantearnos a qué soberanía nos referimos antes de evaluar su vigencia actual en la sociedad post internacional. Pese al desarrollo de esta sociedad, la soberanía

\footnotetext{
${ }^{12}$ Santos Belandro, Ruben. Derecho Comercial internacional. Montevideo. 2008. p. 106 y 107.

${ }^{13}$ Ibáñez Muñoz, Joseph. Poder y autoridad (...) Op. cit. 142 y 143.

${ }^{14}$ Loquin, Éric. Les regles matérielles internacionales. Recueil des Cours. 2006. 322. p. 22 y 23.

Zygmunt Bauman en La sociedad (...) Op. cit. p. 123.

${ }^{16}$ Capella, Juan Ramón. Fruta prohibida (...) Op. cit. p. 257, 259 y 265.
} 
sigue cumpliendo una función esencial en la sociedad internacional de Estados y no se encuentra sustancialmente alterada; lo que sí está ocurriendo, son profundos cambios respecto de la territorialidad y de las capacidades estatales, en ocasiones a favor de autoridades privadas emergentes. ${ }^{17}$

Es cierto que al día de hoy no puede pensarse que la soberanía territorial sea un derecho real de propiedad o cualquier otro derecho que tenga por función asegurarle al Estado el goce de un espacio y de lo que en él se encuentre. Rolando Quadri descarta la idea de que el territorio sea concebido por el Derecho internacional como el objeto de un derecho subjetivo de goce, como una "cosa". ${ }^{18} \mathrm{Al}$ desecharse cualquier representación de naturaleza patrimonial de las relaciones internacionales concerniente a lo que se denomina soberanía territorial, identifica este atributo con la idea de "poder gubernamental" (potestad del gobierno en el sentido del Derecho internacional). ${ }^{19}$

\section{OSCILANDO ENTRE LAS NOCIONES DE ESPACIOS Y DE TERRITORIOS}

Jean-Jacques Lavenue avala esta concepción al afirmar que hoy asistimos al fenómeno de la desterritorialización del Derecho en provecho de un enfoque funcional del mismo, e igualmente de la desterritorialización de la soberanía que fija la autoridad de ese Derecho. Ese fenómeno de desterritorialización ha revitalizado la presencia de dos conceptos: de los territorios, que estarían sometidos al Derecho y a la soberanía de un Estado: territorio estatal, marítimo, aéreo; y de los espacios, que serían lugares que escapan a la apropiación y a la soberanía de un único Estado: espacio extra-atmosférico, alta mar, la Antártida, etc. El territorio pertenece al ámbito de lo público, en el espacio es posible reconocer la actuación de actores privados.

Jean-Marie Pontier profundiza en estos conceptos considerando que "el territorio pertenece al orden de lo público, en tanto que las personas privadas no tienen territorio. Ellas pueden tener tierras, pueden poseer un vasto dominio, pero no disponen de un territorio. Es la diferencia entre el colono que parte para instalarse en otro lado, que busca una tierra para cultivar o sobre la cual instalarse, y aquel que

\footnotetext{
${ }^{17}$ Ibídem, p. 133.

${ }^{18}$ Quadri, Rolando. Droit international cosmique. Recueil des Cours. 1959. 98. III. P. 537 y 595.

${ }^{19}$ Carrillo Salcedo, Juan-Antonio. Droit International (...) Op. cit. p. 62. vol.08, nº. 01, Rio de Janeiro, 2015. pp. 299-349 305
} 
quiere fundar un imperio, un principado o un régimen político. (...) El territorio supone la dominación, una dominación que no es del orden el usus o del fructus -como en el caso del Derecho de propiedad- sino del orden de lo político. Un rey reina sobre un territorio no sobre una tierra. Y en el medievo cuando un señor feudal pretendía ejercer un poder de naturaleza política, su tierra se convertía en territorio. Los conquistadores no son colonos, son conquistadores de territorios que actúan tanto por cuenta de un monarca como por su propia cuenta. El territorio presenta siempre una dimensión política." ${ }^{20}$ Cabe consignar además que el territorio significa algo delimitado; lo que primero fue un simple límite luego se transformó en una frontera en cuyo interior todos los habitantes se hallan sometidos a una autoridad política. Pontier también observa que en la actualidad hay un ataque al territorio tal como se lo ha entendido habitualmente; ese territorio está desvalorizado o descompuesto debido a la multiplicación de otros campos para las norma. "Esas evoluciones van en el sentido de una desaparición del territorio en tanto que soporte de la norma jurídica, esa desaparición se traduce en una alteración del territorio y en una indiferencia creciente de la norma en relación con el territorio". ${ }^{21}$

Basta observar los desarrollos de las nuevas tecnologías, las cuales han venido a dar a ese fenómeno una nueva amplitud: hoy se expresan de manera intensa en el Derecho aplicable al ciberespacio, ya que este último no aparece como un territorio sino como un espacio virtual que escapa al imperio de los Estados, debido a la percepción de un importante rasgo de incoercibilidad. ${ }^{22}$

\footnotetext{
${ }^{20}$ Pontier, Jean-Marie. La problématique du territoire et du droit. Droit et Complexité. Por une nouvelle intelligence du droit vivant. Sous la direction de Mathieu Doat, Jacques Le Goff et Philippe Pédrot. Rennes. 2007. p. 39.

${ }^{21}$ "No quiere decir que la norma no tenga más aplicación territorial lo que no tendría sentido alguno. Va de suyo que toda norma tiene un campo de aplicación territorial y que cuando se habla de territorialización o de desterritorialización no es ese el problema. Lo que se quiere mostrar es que el territorio local determina cada vez menos a la norma, contrariamente a lo que afirman la mayoría de los autores. Esta indiferencia se manifiesta en una cierta disociación de la norma en relación con el territorio, y por la preeminencia del objeto de la norma sobre el marco territorial de la misma. (...) El término territorio no tiene en cuenta la flexibilización que se ha operado. Lo que hace su debilidad (en relación con otros términos) es su aparente insuficiencia de pluralidad de sentidos. Pues no se habla siempre de las mismas realidades al utilizar el término territorio, el cual permanece muy encerrado en una concepción estrecha. (...) No es sorprendente que si el Estado está en crisis el territorio también lo esté". Op. cit. p. 51, 58, 59 y 62.

${ }^{22}$ Lavenue, Jean-Jacques. TIC, souveraineté et ordre public. Http://www2.univlille2.fr/droit(enseignants/lavenue; Idem. Internationalisation ou américanisation du droit public : l'exemple paradoxal du droit du cyberespace confronté à la notion d'ordre public. Lex Electronica. vol.08, $n^{\circ}$. 01, Rio de Janeiro, 2015. pp. 299-349 306
} 
La cuestión de la regulación de espacios como los señalados, se le presentó al Derecho internacional público más anticipadamente y con mayor profundidad, que al Derecho internacional privado. Este último, sólo ha dado soluciones para regular la situación de los buques situados en alta mar o de las aeronaves en "espacios no jurisdiccionales". ${ }^{23}$ Pero ahora nuestra disciplina se ve enfrentada a un reto de talla ante la eventualidad de regular el espacio cibernético o ciberespacio, especialmente el que emerge de Internet.

Desde el Derecho internacional público, y al examinar el Derecho del cosmos, Rolando Quadri llegó a la convicción de que la noción de soberanía no podría retenerse más en su acepción territorial -en cuanto consideraba ridículo extenderla desde el espacio extraterrestre hasta el infinito- sino que ésta deba ser aprehendida en términos funcionales. Su fundamento debe encontrarse en la idea efectividad, y en la imposibilidad de controlar todas las actividades. En el espacio extra-atmosférico no hay soberanía, en la medida que las actividades son incoercibles. Esta mutación en la relación "Derecho-soberanía” y "territorio-espacio" es la culminación de un proceso dialéctico que se halla especialmente vinculado al desarrollo de un enfoque funcionalista del Derecho internacional público.

Para Ibáñez, las instituciones estatales han mantenido su autoridad política en los niveles local, estatal e interestatal, en tanto que en los niveles transnacional y global han sido los actores no estatales los que han hecho valer su autoridad, en ocasiones en detrimento de los gobiernos y de las organizaciones intergubernamentales. Tal como afirmaba el Maestro Quintín Alfonsín hace ya 70 años, las relaciones que se establecen en los diferentes niveles de interacción, pueden llegar a compartir un mismo espacio geográfico, donde el específico espacio político-territorial de los Estados sería sólo uno más. ${ }^{24}$ En suma, el territorio ha dejado de ser un único espacio de interacción social y de

Vol. 11. No. 2. (Automme/Fall 2006). Ibídem. Souveraineté, territoires, espaces, espace virtuel. Cours Commun du Master “Activités transnationales”. 2003-2004.

${ }^{23}$ Tratado de Derecho Civil Internación de Montevideo de 1889. Art. 27. Los buques en aguas no jurisdiccionales se reputan situados en el lugar de su matrícula. Art. 28. Los cargamentos de los buques en aguas no jurisdiccionales, se reputan situados en el lugar del destino definitivo de las mercaderías.

${ }^{24}$ Para el Profesor Alfonsín, las sociedades se contienen unas a otras, y por tanto, se interpenetran, siendo las más generales las que penetran las más especiales. Este fenómeno de interpenetración provoca que los mismos individuos sean sujetos simultáneamente de órdenes jurídicos distintos y que se encuentren obligados a la vez por unos y otros. Por ese motivo nuestra materia no la concibe vol.08, no. 01, Rio de Janeiro, 2015. pp. 299-349 307 
autoridad política y como consecuencia de esta situación, las lealtades de los individuos se orientan hacia autoridades muy diversas, no necesariamente estatales, poniendo de manifiesto paralelamente, la pérdida de peso político en relación con la territorialidad estatal. Por tanto, un mismo espacio geográfico puede albergar una pluralidad de autoridades políticas solapadas, situadas a diferentes escalas, lo cual quiebra o inflexiona principios como el de soberanía, legalidad, jerarquía normativa, derechos subjetivos y ciudadanía. ${ }^{25}$

De este modo se están creando patrones de poder que contribuyen a conformar espacios políticos que no se corresponden estrictamente con la geografía de los territorios soberanos estatales en cuanto a que, como hemos dicho, hay un cambio de ubicación de la autoridad en la política mundial, desplazándose desde los Estados hacia otras fuentes de autoridad no territorial. Ibáñez considera que todavía siguen faltando instrumentos teóricos para analizar la reconfiguración de la territorialidad, para mirar más a los espacios de los flujos en lugar de los espacios de los lugares. ${ }^{26}$ Sostiene que "la globalización económica ha propiciado tanto la transformación del Estado como la emergencia de las autoridades privadas. Son dos procesos simultáneos que se refuerzan mutuamente. El Estado se ha adaptado a las nuevas condiciones de la globalización económica realizando nuevas funciones, dejando que sean otros actores los que desempeñen tareas que antes estaban en manos de las autoridades públicas. ${ }^{27} \mathrm{~A}$ su vez,

más como un derecho interestatal sino más bien, como un orden jurídico intersocial. Alfonsín, Quintín. El orden público. Montevideo. 1938. Farías, José Eduardo. El derecho (...) Op. cit. p. 130.

${ }^{25}$ Loquin, Éric. Les regles matérielles (...) Op. cit. p. 63 y 83. Ver también, Farías, José Eduardo. El Derecho en la economía globalizada. Madrid. 20oo. "De entre las múltiples consecuencias de este fenómeno, una de las más importantes es la superación de las situaciones en que era posible referir las relaciones sociales simplemente a las personas. Los individuos no son y no pueden ser partes de la sociedad y no tiene sentido hablar de participación. Dicho de otro modo, los mismos factores que han provocado la transnacionalización de los mercados de insumos, producción, finanzas, capitales y consumo, también ha acarreado la disolución del individuo como única unidad de acción moralmente relevante.". P. 140.

${ }^{26}$ Ibañez Muñoz, Joseph. Poder y autoridad (...) Op. cit. p. 145 y 147.

27 "El Estado se presenta a la hora actual bajo tres aspectos que -como lo ha expresado el Profesor René-Jean Dupuy- afectan la imagen que de él se hizo en los Tratados de Westfalia. En tanto que estos pretendían la plena soberanía, hoy el Estado debe aceptar estar subordinado; en tanto que proclamaban su integridad territorial, debemos admitir que ella se encuentra seriamente mermada: sus fronteras han perdido mucho de su estanqueidad, el Estado está sumergido; en tanto afirmaba una unidad política que sólo excepcionalmente era puesta en duda, hoy es a menudo un Estado dislocado. En suma, la soberanía no es más lo que era.” Dupuy, René-Jean. Communauté international et disparité de développement. Recueil des Cours de l'Académie de La Haye. 1979. 165. IV. P. 9. Carrillo Salcedo, Juan-Antonio. Droit international (...) Op. Cit. p. 56. 
los actores privados aprovechan las oportunidades económicas de la globalización y asumen funciones políticas que garantizan condiciones más favorables, desplazando en ocasiones, a las autoridades políticas. ${ }^{28}$

La soberanía seguirá existiendo mientras existan los Estados y la sociedad internacional de Estados, aun cuando sea en el marco más amplio de la sociedad post internacional. En los países en vías de desarrollo el Estado no puede ni debe desaparecer debido a que tiene la obligación de intervenir en el ejercicio de una función tuitiva sobre las personas; $y$, en ese campo, no puede ser considerado un extraño, un forastero sino un agente indispensable para el bienestar social. Ahora, si bien la soberanía permanece, territorio y autoridad legítima han cambiado. En lo que respecta al territorio y autoridad legítima éstas sí se han visto profundamente transformadas, es posible percibir una pluralidad de centrismos, una pluralidad de espacios, en lugar de un conjunto de elementos puestos en un espacio común. Hay que re-situar entonces, al Estado.

El ciberespacio. Es ineludible enfrentar el dilema que representa la relación existente entre las tecnologías de la información y las concepciones espaciales de la sociedad. Los cuatro rasgos característicos que distinguen a los mercados electrónicos de los mercados tradicionales son:

1. la transnacionalidad del espacio;

2. la instantaneidad de las transacciones, en virtud de que, según Zygmunt Bauman, "el nuevo espacio es una espacio-velocidad, ha dejado de ser un espacio-tiempo; ${ }^{29}$

3. el anonimato de los operadores; $y$

4. la digitalización de los productos. ${ }^{30}$

\footnotetext{
${ }^{28}$ Ibáñez Muñoz, Joseph. Poder y autoridad (...) Op. cit. p. 131.

${ }^{29}$ Bauman, Zygmunt. La sociedad sitiada. Argentina. 2004. p. 23.

30 "Se trate del mercado de Internet o de los mercados financieros, la desmaterialización de los mercados ha generado una explosión remarcable de nuevas reglas materiales que responden a las necesidad específicas de dicho medio. Las transacciones sobre Internet resultan regidas por normas materiales que forman una lex cibernética o una ciberlex, propuesta tanto por organizaciones internacionales -como por ejemplo la Ley Modelo de la CNUDMI de 1996 sobre comercio electrónico- como por el Derecho regional, tal la Directiva de la UE sobre firma electrónica de 13 de diciembre de 1999, o la Directiva sobre el comercio electrónico de 8 de junio de 2000; como también de origen privado. La aparición de reglas materiales se explica -como fenómeno nuevo- por los nuevos soportes de los intercambios jurídicos. No es más el objeto del contrato y su naturaleza internacional lo que segrega el Derecho material sino su forma inmaterial." Por esta razón, la ciberlex vol.08, $n^{\circ}$. 01, Rio de Janeiro, 2015. pp. 299-349 309
} 
Ante las posibilidades comunicativas que ofrece el ciberespacio algunos autores han considerado que la territorialidad de las relaciones sociales basadas en el espacio físico se verá reemplazada por el uso de las nuevas tecnologías. Otros hablan de coevolución pensando que tanto los espacios electrónicos como los espacios territoriales se irán reproduciendo de un modo conjunto, interactuando entre sí, llevando a cabo una reestructuración constante del sistema político-económico capitalista. Y por último, ubicamos a quienes consideran que se vuelve necesaria una nueva comprensión de las relaciones que están estableciéndose entre tecnología, tiempo, espacio y vida social, donde debe prevalecer la idea de cooperación antes que el viejo concepto de

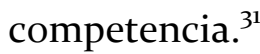

Una de las manifestaciones más importantes de la autoridad privada en la sociedad post internacional es el recurso al soft law, un fenómeno normativo muy amplio y diverso en el que incluyen toda clase de normas no vinculantes que regulan las relaciones entre las partes. El rasgo característico de estas normas es la ausencia de obligatoriedad. Puede distinguirse entre el soft law público, creados por los Estados y organizaciones internacionales gubernamentales $\mathrm{u}$ otras autoridades públicas; el soft law privado, creado por empresas, asociaciones, organizaciones no gubernamentales y otras autoridades privadas; y el soft law híbrido, cuando existe en la creación de la norma una participación mixta de ambos tipos de autoridades. Los Estados recurren cada vez más a normas no vinculantes para implicar más activamente a actores no

intenta aplicarse tanto a las transacciones internas como internacionales. Loquin, Éric. Les règles matérielles (...) Op. cit. p. 39. Ibáñez Muñoz, Josep. Poder y autoridad (...) Op. cit. p. 243.

${ }^{31}$ En el análisis del papel que cumplirá la tecnología en la reconfiguración de la territorialidad Stephen Graham ha identificado tres perspectivas dominantes en torno a la relación existente entre los sistemas de tecnología de la información y las concepciones espaciales de la sociedad. En primer lugar, están aquellas interpretaciones más radicales en clave de "sustitución", según las cuales la territorialidad humana de las relaciones sociales basadas en el espacio físico puede ser reemplazada por el uso de nuevas tecnologías -como lo demostraría las posibilidades comunicativas del ciberespacio-. En segundo lugar, se encuentran aquellas perspectivas de "co-evolución", según las cuales tanto los "espacios" electrónicos como los espacios territoriales se reproducen de manera conjunta, interactuando entre ellos, como parte de una reestructuración constante del sistema político-económico capitalista. En tercer lugar, están aquellas otras interpretaciones en clave de "recombinación", según las cuales es necesaria una nueva comprensión de las relaciones que se establecen entre tecnología, tiempo, espacio y vida social, pues la aplicación de las nuevas tecnologías se produce en un contexto socio-técnico en el que la imbricación de actores humanos y artefactos técnicos es cada vez más profunda. Sea cual sea la perspectiva que adoptemos sobre el papel de las tecnologías de la información en la sociedad, lo cierto es que éstas constituyen uno de los factores determinantes de la "desterritorialización" y "reterritorialización". Y no al margen de los Estados sino dentro y a través de ellos". Ibáñez Muñoz, Josep. Poder y autoridad (...) Op. cit. p. 148. 
estatales en la gestión de algunos ámbitos de la actividad internacional. Para los actores no-estatales las normas no vinculantes del soft law presentan igualmente ventajas, pues a través de ellas es posible influir sobre el comportamiento estatal. ${ }^{32}$

$\mathrm{Si}$ incluimos al ciberespacio en esta tarea de examen de las bases para realizar una codificación, o al menos una sistematización de las normas de derecho internacional privado en el s. XXI, es debido a que el ciberespacio vapulea y zarandea al Derecho y, especialmente al Derecho internacional privado, en cuanto gran parte de la existencia de este último ha estado basada sobre la idea de territorio y de frontera. Las redes electrónicas se mofan de las fronteras nacionales: en Internet no hay fronteras, no hay confines, es un todo unitario, supone el fin de la geografía, un espacio sin costuras como se ha dicho; la noción de territorio no significa nada para él. ${ }^{33}$ Dadas las características técnicas de Internet, las fronteras interestatales son irrelevantes en la medida que no suponen ningún obstáculo al flujo de información entre cualquier tipo de organización o individuo. De ahí que no sea importante el carácter nacional o internacional de las empresas, las transacciones económicas en los mercados electrónicos se producen en un contexto transnacional, no internacional.

Para ser precisos debemos decir que los primeros en preocuparse por la emergencia de este fenómeno tecnológico han sido los geógrafos, seguidos por los filósofos y los antropólogos. Llegan últimos los hombres y mujeres del Derecho, intentando aprovechar los razonamientos interdisciplinarios que les pudieran permitir hacer pie ante esta nueva realidad. Basados en la experiencia adquirida podemos afirmar que el estudio del comercio electrónico confirma la conveniencia de abordar determinados temas desde el eclecticismo teórico, donde el límite a esta técnica estaría marcado por la coherencia. ${ }^{34}$

\footnotetext{
${ }^{32}$ Seidl-Hohenveldern, Ignaz. International economic "soft law". Recueil des Cours. 1979. 163. II. p. 165-246. Zagrebelsky, Gustavo. El Derecho dúctil. Ley, Derecho, Justicia. Madrid. 2007. 7ª. Edición. P. 153.

33 "Si en el mundo real existe una similitud entre "mapa geográfico" y "mapa jurídico", en el mundo virtual esta correspondencia no existe más, y no puede existir." Deffains, Bruno y Fenoglio, Philippe. Économie et ordre juridique de l'espace virtuel. Revue Économique. Vol. 52. Numéro hors série. Octobre. 2001. p. 339. Conforme, Bauman, Zygmunt. La globalización. Consecuencias humanas. Argentina. 2005. p. 20.

34 Por el momento los Estados han logrado hacer prevalecer 5 principios: 1) el de equivalencia funcional; 2) el de inalteración del Derecho preexistente en materia de obligaciones y contratos privados; 3 ) el de neutralidad tecnológica de las disposiciones reguladoras del comercio electrónico; 4) el de la buena fe; y 5) el de la libertad contractual o autonomía de la voluntad.
} 
Internet es un problema que nos incumbe a todos. Es que la actividad electrónica ha invadido todo resquicio de la vida humana: el deporte, la religión, la moda, el sexo, el ocio, la cultura, el conocimiento científico; a través de él puede alentarse al odio racial; pueden cometerse delitos como el ciber terrorismo; en el ciberespacio pueden realizarse propagandas políticas, religiosas, o apoyar campañas militares; en poco tiempo más el contrato electrónico ocupará el lugar del soporte escrito; etc. Nada de lo humano le es ajeno. Y ese espacio transnacional es ocupado por los actores civiles al mismo título que por los Estados.

Internet ha implantado una región no-territorial en la economía mundial, un espacio de flujos descentralizado pero integrado, que existe en paralelo a los espacios de los lugares creados por los Estados nacionales.

Los espacios de lugares convencionales continúan manteniendo relaciones económicas exteriores entre sí, más o menos mediatizados de manera efectiva por los Estados; pero en la región económica global no-territorial, las distinciones entre lo interior y lo exterior resultan muy problemáticas. En un sentido estricto el ciberespacio no puede ser definido como un "territorio" nuevo, a colonizar por los Estados, pues la raíz etimológica del vocablo "territorio" deriva de la palabra "tierra": habitar la tierra, poseer la tierra, hundir los pies en la tierra. Resulta imposible pensar en una actitud como la cumplida por los colonizadores españoles al hacer pie en el continente americano, clavando los estandartes de la cruz y de la espada y considerando a sus habitantes originarios, sometidos al Rey de España y a la fe católica. En primer lugar en Internet no hay "tierra" donde clavarlos. Por tanto, hablar de "territorio" virtual supone un oxímoron, un concepto que contiene sentidos opuestos. ${ }^{35}$

En virtud de lo expresado corresponde realizar una precisión tan importante como la anterior: resulta imposible pensar en la presencia de una espada flamígera de los Estados que ordene las conductas a lo largo $(i$ ? ) y a lo ancho $(i$ ?) de esta nueva realidad debido a que se ha ampliado el horizonte espacial hasta ser sólo uno y, concomitantemente, se ha retraído el horizonte temporal. ¿Cómo hablar de proximidad en Internet? El ciberespacio es un territorio virtual que supera el ámbito de los Estados, su ubicuidad hace que cualquier Estado receptor de un mensaje difundido por la web

\footnotetext{
${ }^{35}$ Schoenborn, W. La nature juridique du territoire. Recueil des Cours. 1929. 30. V. p. 81-161.
} vol.08, nº. 01, Rio de Janeiro, 2015. pp. 299-349 
pueda pretender aplicarle las reglas de su Derecho, y en particular las de su orden público. El funcionamiento de estas reglas choca contra la imposibilidad de ejecutarlas; es indudable que el ciberespacio a-territorial cuestiona a las jurisdicciones estatales.

¿De aquí en más deberían excluirse las teorías zonales, una terminología que presupone la aplicación de un régimen jurídico diferente según la localización de las actividades? Se ha argumentado que el caso Yahoo! es una demostración elocuente de este fenómeno inédito, que coloca a los Estados en un dilema. ${ }^{36}$ Para nosotros el caso Yahoo! está mal planteado por la doctrina, en cuanto ha mirado con preferencia la orden de interdicción del juez de un Estado (el francés) y el rechazo a cumplirla por el magistrado de otro Estado (el norteamericano). Esta situación es absolutamente común y corriente dentro del derecho internacional, en cuanto cada país puede adoptar medidas -y específicamente interponer la excepción de orden público internacionalcuando debido al funcionamiento de la regla de conflicto se ataca su individualidad jurídica. Si se quiere solucionar este problema la mejor manera de hacerlo es celebrando un Tratado internacional; pero repitamos que el problema no está ahí.

Quizás es más sugerente el caso del médico personal del fallecido Presidente François Mitterand de Francia, el Dr. Claude Gubler, quien publicó un libro Le grand secret donde aportaba cuestiones íntimas del Presidente -una de ellas fue que el jefe de Estado no se hallaba en condiciones de ejercer el poder debido a un cáncer prostático algo que se le ocultó a la ciudadanía con informes médicos falsos o parciales- ante lo cual la familia de este último solicitó y obtuvo de la Justicia la prohibición de circulación de la obra y la requisa de los libros. La medida resultó totalmente ineficaz aun cuando, en principio, fue aceptada por el médico de cabecera; pues bastó que un ciudadano francés, Pascal Barbiaud, escaneara la obra completa en un modesto cibercafé de Besançon, y la incorporara a Internet para que circulara libremente por el mundo e incluso en la propia Francia, volviendo inconducente cualquier medida judicial que quisiera atacar esta libertad. El sitio del cual partió la difusión fue luego clausurado, pero la obra igual continúa circulando por todo el mundo, haciendo gala de los tres principios básicos de la cibercultura: igualdad, libertad y gratuidad. Entonces, lo relevante es que existe una imposibilidad de control efectivo por parte de los Estados

${ }^{36}$ Ver Velasco San Martín, Cristos. A propósito de la jurisprudencia y el derecho aplicable en Internet. UNAM. Noviembre de 2005. 
sobre Internet, y más generalmente, sobre el ciberespacio. Es sobre este punto donde debe residir el análisis de estos dos casos judiciales.

A través de ellos estamos percibiendo que nos encontramos ante un exceso de espacio $^{37}$, hay una unidad a escala mundial que perjudica al derecho internacional privado que se basa en compartimentos estancos; se trata de una realidad a-topográfica. En el ciberespacio todo lugar es igual a cualquier otro desde el punto de vista de la localización, a eso se lo llama ubicuidad. El ciberespacio no es inaccesible sino inasible ${ }^{38}$; se han eliminado las "rugosidades físicas" 39 del territorio y la territorialidad, que sólo ve Estados, territorios, fronteras, sitz de las relaciones privadas internacionales, ante lo cual resulta ilusorio cualquier enfoque de derecho internacional privado que únicamente intente encasillar el fenómeno. Todo sitio web una vez creado, inmediatamente se vuelve planetario, cualquier manifestación humana puesta en Internet instantáneamente se plurilocaliza, espacio y tiempo han perdido trascendencia en Internet. Por supuesto, la territorialidad estatal queda exasperada, ${ }^{40}$ la brújula nacional-estatal se enloquece ${ }^{41}$ en cuanto se disuelve en un espacio unitario.

Viajamos entonces por Internet de un lugar a otro, sin ningún movimiento en el mundo real; estamos en el mismo sitio y a la vez no. Se lo ha definido como un espacio simbólico $^{42}$, el cuarto espacio internacional ${ }^{43}$, un meta-territorio ${ }^{44}$ el séptimo

\footnotetext{
${ }^{37}$ Augé, Marc. Los "no lugares" (...) Op. cit. p. 36. ¿Si el mismo lugar está en todos lados, qué importancia tiene entonces el lugar?

${ }^{38}$ Berthou, Renaud. Internet et le respect des principes essentiels du droit du for. Juin. 1999. Ibídem. Le droit au gré d'Internet: à propos d'une réseautisation fort peu anodine de l'univers juridique. Lex Electronica. Vol. 11. Printemps/Spring. 2006. "Para Post y Johnson, los límites físicos no pueden funcionar como signos que informen a los individuos de las obligaciones que adquieren al entrar en un nuevo ámbito legal pues los sujetos desconocen la existencia de dichos límites cuando viajan en el espacio virtual”. Obando P, Juan José. Los contratos electrónicos y digitales.

39 Blanco y Romero, Asunción, y Cánoves Valiente, Gemma. Tecnologías de la información y multifuncionalidad del territorio. asunción.blanco@uab.es

40 "El derecho internacional privado clásico no es apto para aprehender un fenómeno esencialmente inmaterial, en tanto que su técnica reposa sobre la localización de los actos y de los hechos jurídicos en el espacio y en el tiempo. Es ahí donde interviene la doctrina de la gobernanza para dar al fenómeno un marco nuevo de análisis basado sobre un sistema sin jerarquía". Benyekhlef, Seffar y Karim. Commerce électronique et normativités alternatives. University of Ottawa. Law \& Technology Journal. 2006. p. 364 y 365.

(...) Op. cit. p. 364 y 365.

${ }^{41}$ Parisien, Serge. Un essai sur le mode de formation des normes dans le commerce électronique. www.lex-electronica.org

${ }^{42}$ Martínez, Gildardo. Representaciones, discursos y prácticas de actores en torno al ciberespacio. Ponencia presentada en el XXIII Congreso de la Asociación de Estudios Latinoamericanos. Washington D.C. Septiembre 6-8, 2001.
} 
continente $^{45}$; terra incógnita ${ }^{46}$, la a-topía ${ }^{47}$ las metáforas abundan. Ellas son necesarias cuando nos encontramos ante realidades imposibles de definir con exactitud, acudiendo más a la imagen que genera su inteligencia, que a una definición exacta. De todos modos hay que tener bien claro que no se trata de cambios circunstanciales sino de una verdadera mutación de realidad hasta ahora dominante. Lo señalado no quiere decir que el ciberespacio no pueda ser regulado. Para algunos, como Lawrence Lessig, existe una arquitectura y un código, que no son opcionales y que establecen los términos en los que yo puedo ingresar o existir en el ciberespacio. Lessig ha advertido que el código es poder. ${ }^{48}$

En ese mundo nuevo proporcionado por Internet no hay alto o bajo, ancho o largo, próximo o lejano. Entonces nos volvemos a preguntar cómo hablar de proximidad dentro de Internet, y nuevamente interrogarnos si podemos seguir recurriendo a ese criterio tan fundamental en el derecho internacional privado tradicional. Cualquier criterio espacial al cual quiera recurrirse se vuelve totalmente inadaptado. Con él se borra la idea habitual del espacio territorial. Pero también del tiempo, al volver prácticamente instantáneas las respuestas. La percepción de esta situación ha obligado a los legisladores nacionales a admitir que, en numerosas situaciones, habrá que considerar a los contratos celebrados vía Internet como equivalentes a los otorgados entre personas presentes.

También hay que aclarar que si bien las tecnologías constituyen uno de los factores determinantes en los procesos de desterritorialización y re-territorialización. Las propias entidades estatales han contribuido a una reconfiguración de la territorialidad y han usado la tecnología para cumplir sus funciones. Como

\footnotetext{
${ }^{43} \mathrm{Si}$ contabilizamos a la Antártida, al espacio exterior y la alta mar. Menthe, Darrel. Jurisdiction in cyberspace. A theory of international spaces. Michigan Telecomm. Tech. Law Review. 69. 1998. p. 3. No estamos de acuerdo en asimilar Internet a estos espacios pues ello tendría como consecuencia: o re-localizar los actos jurídicos que se realizan en Internet en espacios territoriales -como la mercadería de los buques ubicados en alta mar- algo que conducirá al fracaso; o desconocer la importancia que tienen las transacciones económicas en Internet, lo cual está ausente en los tres espacios antes señalados.

${ }^{44}$ Cammarata, Manlio. Queli leggi per il “territorio Internet”? Interlex. 19 de junio de 1997.

${ }^{45}$ América, Asia, África, Europa, Oceanía, Antártida y Ciberia.

${ }^{46}$ Benayoun, Maurice. Un monde trop humain. Paris. Julio. 1999.

47 Gillet, Alexandre. Derives atopiques. Le "non lieu" ou errantes d'un concept. http//espaces.temps.revues.org/document. 1975.html.

${ }^{48}$ Lessig, Lawrence. Las leyes del ciberespacio. Cuadernos Ciberespacio y Sociedad. No. 3. Marzo, 1999.
} 
consecuencia de esta inmixtión, el Estado ha salido reforzado en algunos ámbitos, en tanto que en otros ha perdido claramente poder.

En el continente americano, por el momento sólo Bolivia se ha preocupado por comenzar a regular este tema desde la óptica del derecho internacional privado. El proyecto de ley elaborado por este país contiene tres artículos (arts. 8o a 82) donde se aborda por primera vez en la región, los problemas que plantean los medios telemáticos. El art. 80 define como "obligaciones telemáticas, aquellas generadas a través de medios electrónicos".

El art. 81 siguiente, establece el Derecho aplicable. Veamos la solución:

Las obligaciones generadas por medios telemáticos se rigen por el Derecho y la jurisdicción indicados por las partes, en virtud del principio de la autonomía de la voluntad.

A falta de indicación válida, estas obligaciones se regirán por el Derecho del domicilio del aceptante de la oferta.

Para estos efectos, no se tomará en cuenta el lugar físico de las computadoras o terminales telemáticas, debiéndose tomar en cuenta únicamente, el domicilio efectivo del aceptante, conforme a lo dispuesto por la presente ley.

O sea que, el principio básico para regular las obligaciones contractuales entabladas o generadas a través de los medios telemáticos es el de la libertad de los otorgantes, no tomando en consideración el criterio de proximidad o el carácter razonable de la elección. Como es necesario un doble régimen en caso de ausencia de manifestación de la voluntad, la solución subsidiaria consiste en recurrir a la ley del domicilio "efectivo" del aceptante de la oferta.

La Sección culmina con una regulación de los hechos ilícitos cometidos por medios telemáticos:

Los hechos ilícitos generados por medios telemáticos, en cuanto a su realización, se rigen por el Derecho del lugar donde se han generado. En cuanto a los resultados, la víctima puede demandar la aplicación del Derecho de su domicilio o del lugar donde se han producido los efectos o del lugar donde se generó el hecho ilícito.

Para efectos de la presente sección, el lugar de la generación del hecho ilícito es el lugar físico de la terminal telemática a través de la cual se realiza el hecho.

De su lectura parece inferirse entonces, que la determinación de cuándo nos encontramos ante un hecho ilícito -en definitiva su calificación como tal- quedará supeditado al Derecho del lugar donde se ha generado, que según el propio proyecto es 
"el lugar físico de la terminal telemática a través de la cual se realiza el hecho". Pero, en cuanto a los daños, la víctima podrá solicitar una reparación eligiendo el Derecho más favorable entre tres posibilidades: el Derecho del lugar de su domicilio, aquél donde se han producido los efectos, o el del lugar donde se generó el hecho ilícito. Quedan supeditados los efectos, a la calificación de ilicitud a realizar por la lex causae.

\section{OSCILANDO ENTRE LOS CONCEPTOS DE PODER Y AUTORIDAD}

El poder. Desde las primeras horas de su existencia, nuestra disciplina analizó el concepto y la aplicación del poder a las relaciones privadas que superaban el ámbito puramente local. Al recurrir los estatutarios a la primera norma del Código de Justiniano -aquélla que establecía la obligatoriedad de adoptar la religión cristiana por todos los habitantes del Imperio- el artículo primero de la Ley Primera decía algo más que eso: "a todos aquellos pueblos del Imperio que están sometidos al poder de nuestra clemencia, les decimos que deben aceptar el dogma de la Santísima Trinidad revelada por el apóstol Pedro (...)”. Apoyándose en una norma de exclusivo corte religioso, los estudiosos medievales llegaron a la conclusión que para dictar normas era necesario detentar un poder, y que la vigencia de la primera habrá de extenderse hasta donde pueda ejercerse el poder de quien la ha promulgado. ${ }^{49}$ En los casos que los estatutarios intentaban resolver, se trataba obviamente de un poder sin soberanía, pues debemos recordar que si bien las ciudades italianas del mediodía gozaban de autonomía jurídica, éstas no eran soberanas, pues se encontraban bajo el protectorado del Emperador de Alemania. Pero, lo que cabe destacar en este momento, es que en base a la idea del

\footnotetext{
49 Gutzwiller, Max. Le développement historique du droit International privé. Recueil des Cours. 1929. 29. IV. P. 302. Meijers, E. M. L'histoire des principes fondamentaux du droit International privé à partir du moyen âge. Recueil des Cours. 1934. 49. III. p. 594. Para Barile ese dualismo entre razones de poder y razones de justicia caracteriza los sistemas modernos de derecho internacional privado. Barile, Giuseppe. La fonction historique du droit International privé. Recueil des Cours. 1965. 116. III. p. 319. "Todo poder, sin importar su clase, supone la posibilidad de imponer en forma real una voluntad a alguien y de sancionar válidamente un desacato; desde el lado pasivo supone tener que acatar los dictados de alguien aún en contra de la voluntad propia. En el caso, no importa que se haga por convencimiento o por temor a la sanción; tampoco importa el tipo de sanción, lo que cuenta es que ésta sea temida". Arteaga Nava, Elisur. El poder. Algunas consideraciones. Boletín de la Facultad de Derecho. España. No.14 (1999) p. 311. J. M. Delgado-Ocando considera que el poder es cualquier relación social regulada por un intercambio desigual. Hacia una comprensión posmoderna del derecho. Dikaiosyne. Venezuela. No. 1. p. 24.
} 
poder -tan importante como oportuna y acertada- y de sus límites, se elaboró un método -el estatutario- al cual se acudió en forma casi obsesiva durante más de 6 siglos.

Según Joseph Ibáñez sobre el poder existen tres concepciones:

1. la sustancialista que concibe el poder como una posesión, como un conjunto de recursos que constituyen un medio para conseguir un fin;

2. la subjetivista, que destaca la capacidad del sujeto de obtener determinados objetivos más que la propia posesión; y

3. la relacional, que alude al poder como una relación entre sujetos en la que uno de ellos modifica el comportamiento del otro, que conduce a la participación en la elaboración de decisiones. En este último caso el poder es la capacidad de un actor para influir sobre otros actores y para conformar el marco de las relaciones entre sí..$^{0}$

El carácter instrumental y el carácter finalista del poder se hallan estrechamente vinculados. El poder es a la vez un medio y un fin: un medio cuando se ejerce para obtener un objetivo, y un fin cuando se aspira a su posesión, porque permite obtener a través de él, los objetivos apetecidos. Y quien posee el poder estructural le permite determinar no sólo la agenda negociadora o las normas de relación entre los actores, sino más ampliamente, el contexto y la forma en que debe darse esa relación. ${ }^{51}$

Las tecnologías del procesamiento de la información y de la comunicación ha tenido consecuencias económicas, sociales y culturales que han llegado a alterar la naturaleza y los patrones del poder en la sociedad internacional: la revolución de la tecnología de la información ha aumentado el peso relativo del conocimiento como fuente de poder, convirtiéndolo en el recurso de poder más importante en las relaciones internacionales contemporáneas; un poder que Ibáñez denomina "suave". ${ }^{22}$

\footnotetext{
$5^{0} \mathrm{~J}$. M. Delgado-Ocando considera que el poder es cualquier relación social regulada por un intercambio desigual. Hacia una comprensión posmoderna del derecho. Dikaiosyne. Venezuela. No. 1. p. 24 .

${ }^{51}$ Ibáñez Muñoz, Jospeh. Poder y autoridad (...) Op. cit. p. 73 y 89.

52 "El conocimiento confiere un poder basado más en el consentimiento que en la coerción, pues es una fuente de autoridad que es reconocida generalmente de forma voluntaria, y que surge del reconocimiento de su importancia para el conjunto de la sociedad. En la estructura del conocimiento este poder a menudo reside más en la capacidad de restringir su difusión y de privar a los demás acceder a él, que en la capacidad de transmitirlo". Ibáñez Muñoz, Joseph. Poder y autoridad (...) Op. cit. p. 89 y 102.
} 
Otro hecho que tiene gran incidencia es que los mercados de la nueva economía y sus operadores han pasado a estar organizados en redes. Las redes son el elemento fundamental del que están y estarán hechas las nuevas organizaciones. La nueva economía funciona según patrones de organización que siguen una lógica de red, una lógica propia de una estructura descentralizada, conformada por nodos y conexiones. El resultado de estas transformaciones en el seno de las empresas ha sido el surgimiento de nuevas formas de organización empresarial en red..$^{53}$

Martin Briot, al referirse a los problemas que genera le regulación del ciberespacio y en especial los de Internet, ante el hecho de la sustitución de la sociedad jerarquizada por una sociedad en red, ha dicho que la autorregulación -consistente en la elaboración y respeto por los propios actores de reglas que han formulado bajo la forma de códigos de buena conducta o de buenas prácticas y a las que ellos mismos aseguran su aplicación- se hallaría mejor adaptada a la sociedad en red, pues eliminaría el vínculo entre soberanía estatal, territorialidad y Derecho. Sin embargo, al examinar la experiencia francesa observa que el Consejo de Estado ha señalado que si bien la autorregulación es una respuesta, ella no puede reemplazar a la ley, en tanto esta última manifiesta la voluntad general, fijando los principios generales, legítimos y obligatorios. El mencionado autor se inclina por pensar en una co-regulación como el mejor de los caminos. Y concluye en el caso específico de "la regulación de Internet, en cuanto ésta sólo puede ser el fruto de una cooperación entre actores privados y actores públicos, aquello que los anglosajones denominan "política de cooperación" entre autorregulación y reglamentación, un mix de prácticas fuera del ámbito jurídico -las recomendaciones- y dentro del ámbito jurídico -legislaciones y reglamentaciones

\footnotetext{
53 De Prada propugna la "red frente a pirámide, asimetría frente a simetría, nodos frente a centro, interdependencia frente a independencia, orden igualitario frente a orden jerárquico". Recordando a Manuel Castells piensa "en un Estado caracterizado por compartir la autoridad (es decir, en último término, la capacidad de imponer la violencia legitimada) a lo largo de una red. Los datos disponibles y los debates recientes de la teoría parecer sugerir que el Estado-red, con su soberanía de geometría variable, es la respuesta de los sistemas políticos a los retos de la globalización. La Unión Europea puede ser la manifestación más clara hasta la fecha, de esta forma de Estado emergente, probablemente característica de la era de la información." De Prada García, Aurelio. Pirámides y redes: el concepto de Derecho. Boletín de la Facultad de Derecho. España. 1999. No. 14. p. 194. Ver además: Messner Dirk. La sociedad de redes. 1995.
} 
administrativas- quedando la última palabra en manos de la reglamentación". Compartimos su punto de vista. ${ }^{54}$

"La eficacia cognitiva de la metáfora de un poder (político) agente de un orden causal, puesto en movimiento por voluntad de ese agente, se daba por supuesta. (...) Con la gran transformación -acota Capella- comprender los fenómenos de poder general (lo que hasta ahora llamábamos poder público) deja de ser asequible en esos sencillos términos. Si se quiere conservar de algún modo la idea de determinación de la vida social por entidades dotadas de poder es preciso recurrir a alguna metáfora más compleja, como puede ser la noción de la física moderna del campo de fuerzas. Esto es: hay que prescindir de la idea de un único agente causal y pasar a hablar de un ámbito en el que se suscitan determinaciones, aunque éstas no puedan ser atribuidas linealmente a un solo agente generador, o incluso aunque en una situación concreta la determinación del generador quede obscurecida o sea imposible dentro del campo. Se trata de determinaciones interrelacionadas". 55

La introducción de un nuevo concepto: la autoridad. Adoptando una actitud prudente, el catalán Joseph Ibañez realiza un aporte teórico importante que es el siguiente: habitualmente se ha considerado a la autoridad como la autoridad pública, y

\footnotetext{
${ }^{54}$ El autor considera que hay otro modo de producción normativa, donde el Estado debe adaptar sus modos de intervención a un mundo nuevo, sería un Derecho negociado que tomaría el lugar de un Derecho impuesto. Esta nueva normatividad respondería a dos crisis: a la crisis del Estado como modelo burocrático, weberiano, estato-céntrico, con sus normas de expresión de la voluntad soberana y trascendente que se expresa desde lo alto del Olimpo; y la crisis del mercado, donde es necesario conciliar de alguna manera dos intereses contradictorios: el mantenimiento de la competencia y la preservación de los intereses de los servicios públicos. (...) De esta manera, a la horizontalidad de Internet, a su concepción policéntrica, a su incesante extensión, la verticalidad de la intervención estatal -jerarquizada por definición- se encontraría profundamente inadaptada, impotente de hecho: deberíamos ver una horizontalidad de las fuentes normativas, un Derecho plural, pluralismo ordenado bajo el control del Estado, figura central y no ya super aplomado, la pirámide jerarquizada de los positivistas; las normas estarían a la vez encajonadas pero también entrelazadas, lo que deja descolocada a la idea euclidiana del Derecho; el Derecho plural se construiría mediante ajustes sucesivos, el Estado no sería ya más, el único ámbito del Derecho". Briot de La Crochais, Martin. La régulation d'Internet.

55 'El poder 'político' ha modificado su estructura profunda con la gran transformación; por vez primera desde el nacimiento de la modernidad no puede ser descrito en términos de soberanía y legitimidad simples. El campo de poder contemporáneo está constituido por la interrelación de un soberano privado supraestatal difuso y -puesto que se mantiene la base territorial de asentamiento del poder- un 'Estado permeable' o unas 'asociaciones estatales' permeables, abiertas o porosas (como puede ser la Unión Europea). Análogamente, deja de ser cierto que el sistema de legitimación reconocido en el relato político aceptado -en las metrópolis occidentales, el relato democráticorepresentativo- sea el único operante: el campo de poder admite la co-presencia de distintos sistemas de legitimación”. Capella, Juan Ramón. Fruta prohibida. (...) Op. cit. p. 257.
} 
la esfera privada como un ámbito diferenciado, aislado o sometido a la primera, disociación estrechamente vinculada a la separación entre lo político y lo económico. Recuerda que Bertrand de Jouvene ${ }^{56}$ distinguía el uso jurídico del término autoridad (Autoridad) del uso político (autoridad). En el sentido jurídico la autoridad comporta un derecho a mandar e implica una obligación de obedecer. Cada ordenamiento jurídico determina formalmente quién o quiénes son las Autoridades y cuáles son sus competencias, en este sentido la Autoridad es un concepto estático. En el sentido político es algo más amplio e indefinido, aludiendo a la posición de deferencia en la que se encuentra un sujeto político respecto de otro; esta posición puede variar en extensión e intensidad y, en este caso la autoridad es un concepto dinámico. ${ }^{57}$

Por definición, las Autoridades son conservadoras, pues sus probabilidades de supervivencia son inversamente proporcionales a la emergencia de otras autoridades, de ahí que las Autoridades jurídicas hagan lo posible por neutralizar a las autoridades políticas competidoras. Esta distinción entre autoridad jurídica y autoridad política le permitió explicar el surgimiento de la autoridad política (autoridad) al margen de las autoridades jurídicas (Autoridad)..$^{5}$

El papel de la autoridad es crucial para la comprensión del poder, pues para perdurar todo poder necesita asentarse sobre la autoridad y ésta puede hallarse en un actor o en las estructuras. La autoridad se ubica en un punto medio entre la persuasión y la coerción. La coerción es un elemento prescindible en el proceso, pues a diferencia de la autoridad, puede generar por sí sola el consentimiento, pero no un consentimiento con reconocimiento público. Si los dos elementos latentes -los de

\footnotetext{
${ }^{56}$ De Jouvenel, Bertrand. The pure theory of politics. Liberty Fund. 1963. p. 100 y 101.

57 "Para González Casanovas la autoridad aparece cuando el poder político tiene la capacidad de ganar el asentimiento de los miembros de la comunidad, cuando puede basarse sobre una capacidad que habilite a una elaboración razonada. La autoridad no es una cosa que se tenga sino una cualidad de quien ejercita el poder. Por tanto, la autoridad se encontrará allí donde sea evidente la existencia de dicha capacidad, no residirá necesariamente en las autoridades públicas. Éstas son incapaces de monopolizar la cualidad de la autoridad. Por tanto, hay que distinguir entre la autoridad como cualidad, de la autoridad como entidad. La autoridad es una cualidad de las autoridades públicas pero también de las autoridades privadas. A medida que una persona practica comunicaciones cada vez más autorizadas, a medida que se convierte en una autoridad, va ganando poder. Al principio ese poder es informal, no es oficial, y reviste la forma de una influencia. Hay personas o grupos influyentes porque tienen autoridad. Su opinión sienta autoridad." Ibáñez Muñoz, Joseph. Poder y autoridad (...) Op. cit. p. 161 y 162.

${ }^{58}$ Ibáñez Muñoz, Joseph. Poder y autoridad (...) Op. cit. p. 165.
} 
persuasión y los de coerción- se hacen efectivos, está indicando un declive de la autoridad y, consiguientemente un declive del poder, especialmente del poder legítimo.

El reconocimiento de la relevancia de los actores no estatales en las relaciones internacionales está forzando a replantear la naturaleza del poder, en cuanto siempre había sido caracterizado como un poder estatal, un poder referido a las capacidades propias de los Estados y ubicado dentro del marco de las relaciones interestatales. Conviene entonces, realizar un replanteo teórico del concepto de poder para arribar a una concepción que permita abrazar e integrar a todo tipo de formas y manifestaciones de poder, no sólo las de poder estatal..$^{59}$

El declive de la autoridad estatal se ha manifestado tanto en la dispersión creciente de la autoridad entre otras instituciones y asociaciones y entre órganos locales y regionales, como también en una asimetría creciente entre los Estados mayores con poder estructural, y aquellos otros menores que no tienen este poder. Del panorama expuesto se deduce pues, que resulta necesario propender a crear un orden en el relacionamiento de todos los actores, yendo, si es necesario, a una reformulación del poder estructural. ${ }^{60}$

Y López Ruiz señala que "es habitual que quien ostenta una determinada autoridad disponga también de poder; pero pueden darse casos tanto de autoridad sin poder como de poder sin autoridad. Una persona o una institución con autoridad suele ser una persona o institución con poder. Pero la autoridad implica algo más que el poder."

En esta tarea de agregar normatividad a las relaciones privadas internacionales que está reclamando la participación de numerosos actores, a los cuales se les reconoce autoridad política- es posible encontrar en el ámbito regional algunas Convenciones internacionales que estaría confirmando lo expresado. La primera de ellas es la

\footnotetext{
${ }^{59}$ Ibídem, p. 185 y ss.

${ }^{60}$ Peces-Barba comenta que "en el marco histórico del mundo moderno, el ordenamiento jurídico está apoyado en el poder. El fundamento último de la validez de un sistema jurídico está en el poder. Cuando hablamos de poder queremos decir sobre todo, aunque no exclusivamente, poder del Estado, que es la forma de organización moderna del poder político. Pero no queremos dar al binomio Estado-Derecho un carácter excluyente. Lo importante de nuestra afirmación es que en la sociedad moderna el Derecho funda su validez en la posibilidad que tiene el poder en última instancia y en caso de incumplimiento, de imponerlo por la fuerza. Ese poder suele ser el poder del Estado pero no es una identificación esencial. Puede ocurrir que en una sociedad concreta, lo detente un grupo social que no sea el Estado.”Peces-Barba Martínez, G. Introducción a la Filosofía del Derecho. Madrid. 1983. p. 51.
} 
Convención Interamericana sobre arbitraje comercial internacional, que en el art. 3 sentencia que a falta de acuerdo expreso entre las partes, el arbitraje se llevará a cabo conforme a las Reglas de Procedimiento de la Comisión Interamericana sobre Arbitraje Comercial, consagrando por tanto, una especie de delegación legislativa en manos de una institución privada, como es la Comisión Interamericana sobre Arbitraje Comercial (C.I.A.C.).

Algo más tarde encontramos el inciso segundo del art. 9 de la Convención Interamericana sobre derecho aplicable a los contratos internacionales, el cual consigna que

El tribunal tomará en cuenta todos los elementos objetivos y subjetivos que se desprendan del contrato para determinar el derecho del Estado con el cual tiene vínculos más estrechos. También tomará en cuenta los principios generales del derecho comercial internacional aceptados por organismos internacionales.

En la C.I.D.I.P. V, fue insistente la prédica de los Delegados de México Leonel Péreznieto Castro y de Perú Aníbal Sierralta Ríos, en aclarar que la referencia a "organismos internacionales" no hacía alusión a organismos interestatales sino a cualquier organismo -público o privado- que contara con credenciales suficientes (que tuviera autoridad) en el ámbito internacional para realizar y confiarle esa tarea. No existe un trámite de acreditación preciso que determine cuáles son esos "organismos internacionales", sino que la calidad de autoridad surgirá de un análisis del caso concreto y de la convicción que tenga el juez de que el "organismo internacional” público o privado-, goza de una objetividad y de una actuación internacional ciertas; posición que fue la asumida por la Conferencia. ${ }^{61}$

Asimismo contamos con el Acuerdo sobre Arbitraje Comercial Internacional del MERCOSUR. Su art. 10 señala que las partes podrán elegir el Derecho que se aplicará para solucionar la controversia en base al derecho internacional privado y a sus principios, así como al derecho del comercio internacional. Si las partes nada dispusieran en esta materia, los árbitros decidirán conforme a las mismas fuentes.

Resulta claro que en ese relacionamiento, las reglas de juego no serán impuestas como antaño en forma exclusiva por los Estados; sino que habrá una tarea, o bien de co-

\footnotetext{
${ }^{61}$ Quinta Conferencia Especializada Interamericana sobre DIP. (CIDIP-V) Ciudad de México. 14 a 18 de marzo de 1994. Vol. I. Segunda Sesión Plenaria. 16 marzo 1994. p. 27. 
legislación y de reconocimiento mutuo más o menos intenso; o bien de prescindencia y hasta de hostilidad beligerancia entre las diferentes fuerzas generadoras de normas. Sin duda, un panorama sumamente atractivo para el analista. Por un lado, el juez podrá ir abandonando la tarea de mero aplicador del Derecho con carácter exclusivo, para intervenir activamente en el proceso creativo de la norma jurídica; y por el otro, no sólo tendremos al legislador estatal o nacional, sino que a él se le sumarán legisladores de orígenes muy diferentes (no precisamente estatales), con credenciales de validez asíntonas.

No queremos finalizar el tratamiento de esta sección sin antes hacer mención al hecho de que los propios Estados han admitido la porosidad de sus fronteras, las cuales ya no son más concebidas como la línea que fortalece la existencia de comportamientos estancos, a través de los cuales no se puede circular si no es sometiéndose a una serie de gabelas y de autorizaciones. En lugar de conformarse como una línea divisoria apta para adjudicar competencias, se transforma en una zona de comunicación. A título de ejemplo, la Convención Interamericana sobre exhortos y cartas rogatorias de 1975 establece en su art. 7 que los tribunales de las zonas fronterizas de los Estados Parte podrán dar cumplimiento a los exhortos o cartas rogatorias previstos en esta Convención en forma directa, sin necesidad de legalizaciones.

\section{LA SOCIEDAD POSNACIONAL}

Según el Profesor Friedrich Juenger lo común en nuestra disciplina ha sido la falta de certeza acerca de la utilización del enfoque apropiado para regular las cuestiones de tráfico jurídico transfronterizo. ${ }^{62}$ Renovando una vez más la interrogante podemos preguntarnos si existe hoy realmente una sociedad internacional como fundamento del derecho internacional privado, si ella constituye un todo armónico o una realidad problemática. En caso de negativa acerca de su existencia, deberíamos igualmente analizar si resulta de utilidad el concepto, entendido como un horizonte de sentidos que crea todo agrupamiento humano que quiera entenderse como tal.

\footnotetext{
${ }^{62}$ Juenger, Friedrich, K. General Course of Private International Law. Recueil des Cours. 1985. 193. IV. P. 131. 
Para algunos la expresión sociedad internacional podría ser equivalente al de sociedad civil, entendida como aquella esfera social que no se encuentra regulada por el Estado y que está compuesta por individuos. El Estado era concebido como el conjunto de los aparatos que en un sistema social organizado ejerce el poder coactivo. Como hemos señalado, la dicotomía sociedad civil-Estado surgió en el s. XIX, y fue tomada como una contraposición -desconocida por la tradición- entre una esfera política y una esfera no-política. ${ }^{63}$ Desde entonces no ha sido posible delimitar la extensión de la sociedad civil si no es refiriéndose y delimitando, al mismo tiempo, al término Estado. ${ }^{64}$ Esta contraposición entre sociedad civil y sociedad política se abrió paso con el nacimiento de la sociedad burguesa y fue la consecuencia de una diferenciación que se presentó en la división de funciones entre quienes se ocupaban de la riqueza de las naciones y quienes se ocupaban de las instituciones políticas.

En el Río de la Plata, a fines del s. XIX, los sujetos creadores de normas de derecho internacional privado no fueron los particulares sino los Estados, cuya función fue determinar los derechos y deberes recíprocos de los Estados para regular las relaciones jurídicas de orden privado. En definitiva: delimitar la competencia legislativa y judicial de cada Estado y resolver los conflictos de soberanías. Esta concepción condicionó el método a seguir: un método de conflicto de leyes ideado por y para los Estados, dotado además, de una naturaleza preceptiva. Los Estados y sus órdenes jurídicos, se presentaban a fines del s. XIX, como apropiándose totalmente de la sociedad internacional, ellos eran la sociedad internacional.

\section{LA CONCEPCIÓN DE LA SOCIEDAD INTERNACIONAL EN LA DOCTRINA EUROPEA}

¿Tertium non datur? Los razonamientos precedentes permiten plantearnos la interrogante de si el concepto de sociedad civil -en cierto modo en oposición respecto del Estado- en realidad puede aplicarse a la sociedad internacional tomada en consideración por nuestra disciplina. La aparición del Estado moderno ha llegado a

\footnotetext{
${ }^{63}$ Bobbio, Norberto. Estado, Gobierno y Sociedad. México. 1991. p. 39 y ss.

${ }^{64}$ Santos Belandro, Ruben. La sociedad internacional como fundamento del derecho internacional privado. Direito e Comércio Internacional. Tendências e perspectivas. Estudos em homenagem a Irineu Strenger. Sao Paulo. 1994. p. 67.
} 
marcar de tal modo al derecho internacional privado, que éste ha permanecido unido a los marcos estatales, en los cuales y en gran parte, se elabora y se aplica a través de las actividades legislativa y jurisdiccional. Al respecto nos parece que la concepción puramente estatista de la materia aparece hoy ampliamente superada: el progreso ius internacional privatista ha dependido en los últimos tiempos, de un reconocimiento ampliado a las entidades sociales, las cuales participan en la actualidad en el desarrollo de nuestra ciencia y de la presencia de diversas fuentes de producción jurídica.

Como expresa el Profesor François Rigaux, aún cuando se reconozca que únicamente los Estados son los que detentan la posibilidad de plantear nuevas reglas, una visión puramente estatista de esta disciplina resulta inadecuada, debido a que desdeña a muchas "galaxias" no-estatales. ${ }^{65}$

En la doctrina se va imponiendo lentamente una hipótesis pluralista que permite apreciar en su campo, múltiples y diversificados órdenes jurídicos -estatales o noactuando unos sobre los otros. El perfil de la sociedad internacional es el de una sociedad fraccionada o policéntrica en cuyo ámbito no sólo actúa el Estado moderno, caracterizado por la posesión permanente y exclusiva de un territorio y de una situación de mando sobre sus habitantes, sino que igualmente se reconoce la actuación de agrupamientos sociales en diversos grados de evolución, con distintos grados de totalidad o unidad, con diferentes modos de interacción y variados grados de entidad y sistematicidad. En definitiva, lo que se busca es plantear y reconocer nuevas vías de acceso a la normatividad: precisar quién puede crear la norma, quién la puede cambiar y cómo puede se la puede cambiar.

Santi Romano, afirmó en su momento, que no sólo los Estados sino cualquier cuerpo social podía llegar a crear un orden jurídico. ${ }^{66}$ Todo lo que es Derecho no puede

\footnotetext{
${ }_{5}^{65}$ Rigaux, François. Les situations juridiques individuelles dans un système de relativité générale. Recueil des Cours. 1989. 231. I.

${ }^{66}$ Para Romano el derecho estatal sólo es una especie del género Derecho, ya que perfectamente puede concebirse el Derecho sin el Estado. El sistema estatal no es el único sistema jurídico. Una concentración tal de lo jurídico en el Estado, le resulta materialmente imposible. Hay órdenes jurídicos que cuentan con autoridades legislativas, ejecutivas y con sus tribunales. Rehusarles la calidad de orden jurídico sólo puede partir de un juicio moral al cual es extraño al Derecho. Todo cuerpo social es portador de Derecho -y, más aún- él es Derecho. Reconocida la existencia de una pluralidad de ordenamientos jurídicos, la segunda cuestión que Romano se plantea es la del relacionamiento entre dichos órdenes, en la medida que cada uno tiene en cuenta o existe o es relevante, en función del otro. En esa óptica va examinando a las instituciones en: simples y complejas, perfectas e imperfectas, con o sin personería jurídica, independientes, coordinadas y vol.08, nº. 01, Rio de Janeiro, 2015. pp. 299-349 326
} 
ni debe serle imputado a los Estados. Si bien se ha tenido el hábito de representar al Estado como una institución con fines ilimitados, en realidad, para el autor italiano ello significa que no existe ningún fin social que el Estado no puede atribuirse; pero sólo constituye la afirmación de una potencialidad virtual, de una posibilidad abstracta, debido a que en lo concreto, el Derecho de cada Estado busca limitarse en cuanto a las materias que quiere regular. ${ }^{67}$ Existen numerosos tópicos sobre los cuales el Estado se desinteresa y no tiene ningún motivo para tomarlos en consideración, aun cuando pueda preverse que otro orden jurídico pueda llegar a regularlos. Abandona ciertas áreas, ya sea reconociendo la imperfección del orden estatal, la falta de agilidad en la regulación del fenómeno jurídico, la escasa relevancia o la gran complejidad de ciertas materias, etc.

A medida que el Estado se afirmó y su fuerza y hegemonía fue profundizándose sobre comunidades hasta ese momento rivales e independientes, podía creerse que la unificación del orden jurídico estaba cumplida, y de este modo llegar a la convicción de que el Estado era el señor y el dueño, no sólo del Derecho sino de todo el Derecho. Pero, la acción de contener lo jurídico "dentro de las murallas del absolutismo estatal" le ha parecido al Profesor Phocion Francescakis una tarea absurda, puesto que hay tantos órdenes jurídicos como instituciones. ${ }^{68}$

Por su lado, Jean Déprez aboga por un enfoque sociológico del Derecho internacional privado de manera de permitir examinar de otra manera el juego de los mecanismos fundamentales de los conflictos de leyes. ${ }^{69}$ Ello supone una renovación del discurso conflictualista que habilite restituir lo humano y lo social a su justo plano, permitiendo que el operador jurídico pueda escapar al exceso de teorización y a los riesgos de una concepción desencarnada, cerebral y mecánica del Derecho internacional privado. Si bien para Déprez los Estados se han constituido en una pieza maestra del

subordinadas. No obstante, Romano fue un pluralista moderado, creía en los beneficiosos efectos que emergen de los grupos sociales que pueden producir una mayor articulación de las relaciones entre los individuos particulares y el Estado, pero siempre consideró al Estado como el momento final y necesario de una sociedad organizada. Romano, Santi. L'ordre juridique. Paris. 1975. Pág. 1 y ss.

${ }^{67}$ Francescakis, Phocion. Introduction à l'édition française a la obra de Santi Romano: L'ordre juridique. Paris. 1975. p. X y este último autor en p. 104.

${ }^{68}$ Ibídem. p. XV.

${ }^{69}$ Déprez, Jean. Droit international privé et conflits de civilisations. Aspects méthodologiques. Les relations entre systèmes d'Europe Occidentale et systèmes islamiques en matière de statut personnel. Recueil des Cours. 1988. 211. IV. p. 8. 
juego internacional, considera que el campo natural de éstos es el de las normas jurídicas más que el de las realidades sociológicas.

Afirma que esta situación no debe sorprender puesto que el Derecho internacional privado por mucho tiempo ha sido un producto del Estado: la referencia jurídica necesaria -las leyes en conflicto- son las de los Estados; las sentencias judiciales extranjeras deben pasar por el filtro del exequátur a cargo del Estado extranjero; un funcionario estatal será quien actúe en la calificación de las relaciones jurídicas; los puntos de conexión se encuentran siempre en relación con los Estados; etc. Este enfoque ha conducido a que los modos de agregación de las personas no sean observados bajo el plano sociológico o cultural, como la pertenencia a un pueblo, a una nación, a una etnia o a otro tipo de comunidad. ${ }^{70}$ Déprez considera que examinando la vida internacional a través de la pantalla de los Estados nos hemos acostumbrado a retener la noción de comunidad internacional en su acepción más jurídica, la cual le proporciona la mejor parte a los Estados. De ahí que el Derecho internacional privado se haya interesado más por las entidades político-jurídicas como los Estados, que por las entidades sociológicas que componen la comunidad humana. A primera vista, parecería que el juez no tiene ocasión de plantearse la presencia relevante de otras entidades más que las estatales.

Rigaux continúa las ideas de Déprez, poniendo de relieve que existen porciones enteras del comercio internacional que resultan sustraídas de las instituciones estatales: la explotación económica del deporte; el entorno bancario que ha creado monedas propiamente deslocalizadas; la existencia de sociedades que si bien han sido creadas bajo diferentes Estados, sin embargo pertenecen a un grupo transnacional, y sobre las cuales no existe una opinión coherente de su personalidad; los bienes con valor económico han tomado nuevas formas que los sustraen a los procedimientos tradicionales de la coacción física; los derechos intelectuales se hallan regidos por mecanismos contractuales de origen privado; el savoir faire o el know-how, la tecnología de avanzada, el establecimiento de circuitos transnacionales de producción y comercialización de bienes manufacturados que resultan sustraídos del control estatal. Además, numerosos contratos internacionales hacen referencia al Derecho

\footnotetext{
${ }^{70}$ Déprez, Jean. Op. cit., en el Capítulo: Pour une approche sociologique du droit international privé.
} P. 219 . 
internacional, a los principios generales de derecho o a los principios comunes a varios ordenamientos jurídicos estatales, a los usos del comercio, etc. En virtud de lo expuesto Rigaux considera que entre el Derecho estatal y los ordenamientos jurídicos transnacionales deben reconocerse relaciones semejantes a las que tienen los ordenamientos jurídicos estatales entre sí. ${ }^{71}$

Según el referido autor, la sociedad sobre la que el Derecho estatal organiza su existencia, se caracteriza por la reunión de tres elementos: una población, un territorio y un orden institucional. Sin embargo, este triple criterio de delimitación espacial sería un simple modelo formulado por la ciencia jurídica, pero que carece de consecuencias sobre el Derecho positivo. Para el doctrino este modelo no es completo, porque existen situaciones que no derivan del Derecho estatal. En numerosos aspectos el espacio real en tres dimensiones se ha vuelto un espacio común a la totalidad de los ordenamientos jurídicos, quedándole al Estado el ejercicio de los actos de coacción física, único y exclusivo objeto del poder territorial. Al igual que Déprez concluye que es necesario un modelo remozado de Derecho internacional privado que tenga por efecto útil, denegarle a los ordenamientos jurídicos estatales una pretensión a la universalidad espacial. ${ }^{72}$

De la idea de armonía sustantiva a la idea de respeto a la diversidad. A través de este recorrido hemos podido constatar la lenta evolución que ha experimentado la imagen de la sociedad internacional dentro del derecho internacional privado. De la primitiva idea de un mundo reconciliado y armónico alrededor de determinados principios fundamentales reconocidos por las entidades jurídico-políticas que constituyen los Estados Naciones, se ha llegado por un lado, a un cuestionamiento a la identificación del orden con la armonía; y por el otro, a un debate sobre el número de

\footnotetext{
${ }^{71}$ Rigaux, François. Les situations (...) Op. cit. p. 81.

${ }^{72}$ Ibídem. P. 106 y 107. Considera que para la concreción de un nuevo modelo se vuelven necesarias cuatro pautas: constatar el funcionamiento de los distintos ordenamientos jurídicos positivos; definir el Derecho de forma que no excluya manifestaciones no estatales del orden jurídico; atender tanto a los derechos subjetivos creados por un orden jurídico como a los que se ubican parcialmente en varios de entre ellos; y abrir las vías de cooperación o compromiso, eliminando cualquier clase de bloqueos. P. 93. Para Santi Romano, "toda institución toma forma concreta de un orden jurídico distinto, que puede no encontrar fundamento y apoyo en el orden estatal (...) al concepto de comunidad nosotros preferimos el de institución, más amplio, más completo nos parece, además de ser más esencialmente jurídico". Romano, Santi. L’ordre juridique. Op. cit. p. 96 y 97. Según Zygmunt Bauman "el centro de control ahora se ha ocultado y ya no lo ocupa ningún líder conocido ni una ideología clara” La modernidad líquida. Argentina. 2002. p. 143.
} 
entidades participantes del Derecho internacional privado. Se percibe un movimiento expansivo que no sólo busca comprender a los fenómenos estatales sino también a otros fenómenos igualmente jurídicos pero extraestatales.

Esta nueva realidad resulta, en gran parte, del cuestionamiento de que son objeto las verdades universales impuestas por el Iluminismo y del descaecimiento abrupto en las masas sociales de los metarrelatos. Al producirse un desgaste de las verdades totalizadoras, el orden posible ya no representa la reunificación armoniosa de la sociedad sino que deberíamos verla tal como ella se presenta: como un permanente conflicto en el cual el número de participantes se ha ampliado notablemente.

De la actuación en el S. XIX hasta mediados del s. XX de un puñado de Estados independientes -en su mayoría europeos y americanos- se ha pasado a un aumento notable de entidades estatales mediante un profundo proceso de descolonización y de la fragmentación de ciertos países europeos y euroasiáticos. Concomitantemente con esta situación han surgido y afianzado numeroso organismos internacionales gubernamentales y no gubernamentales- en las más diversas áreas, cuya presencia y audiencia en el ámbito internacional vuelve imposible prescindir de las mismas.

Además, una cantidad cada vez mayor de personas jurídicas de origen privado ha tomado al espacio transnacional como el ámbito propio de actuación. La franja del Derecho comercial internacional paulatinamente ha ido organizándose en forma extraestatal, por intermedio de corporaciones de comerciantes, Cortes de Arbitraje, codificación de usos mercantiles; que en conjunto han ido conformando para muchos, una sociedad de mercaderes o mercática, dotada de su propio Derecho: la lex mercatoria. En la actualidad ya no puede establecerse una neta división entre las entidades que forman parte de nuestra disciplina y aquellas que están excluidas, debido a que actualmente, espacio de poder y espacio de acción no son conceptos necesariamente coincidentes. ${ }^{73}$

\footnotetext{
${ }^{73}$ Este autor considera que no debe partirse de una noción falsa de la comunidad internacional en cuanto concebida como un mundo reconciliado, pues puede dar la impresión de que estaríamos ante una comunidad fraterna donde conflicto y comunidad parecen ser incompatibles. Afirma que para existir, la comunidad no puede ignorar el conflicto. Un concepto supone al otro. En el análisis hay que reintroducir la interdependencia y el antagonismo. Dupuy, René-Jean. Communauté international (...) Op. Cit. p. 9.
} 
El reconocimiento de un sistema tan complejo provoca sin duda, una asimetría en las orientaciones hacia el objeto propio del derecho internacional privado. No todas las entidades se orientarán hacia el ámbito internacional con la misma intensidad y con la misma amplitud; comprobándose asimismo, una distribución diferencial del poder. Por tal motivo, el orden que resulte de este entorno problemático resultará de un proceso negociado, en el que adquirirá una extraordinaria relevancia la herramienta metodológica a utilizar. Ante un mundo tan diversificado -ante un pluriverso socialdesde un punto de vista lógico y empírico corresponde enriquecer el arsenal metodológico que nos conducirá al respeto de ese pluralismo normativo.

\section{LA CONCEPCIÓN DE LA SOCIEDAD INTERNACIONAL EN LA DOCTRINA URUGUAYA}

Hemos analizado en diversas oportunidades, las características que rodeaban a la sociedad internacional tal como la examinó el Derecho internacional privado y mencionábamos la existencia de dos corrientes de pensamiento contrapuestas dentro de la doctrina uruguaya. La defendida por el Profesor Gonzalo Ramírez en el s. XIX, quien concebía a la sociedad internacional como un club cerrado, compuesto por entidades políticas de igual naturaleza: los Estados. Y la sustentada por el Profesor Quintín Alfonsín con su visión sociológica de una sociedad internacional compuesta de individuos. $^{74}$

Al día de hoy resulta imposible apoyar cualquiera de las dos corrientes de pensamiento en su estado de pureza y, en lo personal, somos partidarios de una

\footnotetext{
${ }^{74}$ Ver Santos Belandro, Ruben. Las nociones de sociedad internacional y Estado: dos claves para ingresar al derecho internacional privado uruguayo. Avances del Derecho Internacional Privado en América Latina. Liber Amicorum Jürgen Samtleben. Coordinadores Jan Kleinheisterkamp y Gonzalo A. Lorenzo Idiarte. Montevideo. 2002. p. 207 y ss. Ianni al referirse a la desterritorialización agrega: "poco a poco o de repente, el mundo se hace grande y pequeño, homogéneo y plural, compuesto y multiplicado. Simultáneamente a la globalización, se dispersan los puntos de referencia dando la impresión de que se mueve, flotan, se pierden. Ni siquiera los centros de decisiones mundiales más fuertes pueden considerarse absolutos o incuestionables. Pueden ser llevados a anularse o a declinar gracias al juego de fuerzas que operan a nivel mundial. Las relaciones, los procesos y las estructuras de dominio y apropiación, integración y antagonismo, frecuentemente disuelven fronteras, locales de mando, referencias. La verdad es que declina el Estado-Nación, aun el metropolitano, dispersándose los centros de decisión por diferentes lugares, empresas, corporaciones, conglomerados, organizaciones y agencias transnacionales. Se globalizan las perspectivas y los dilemas sociales, políticos, económicos y culturales. " Ianni, Octavio. La sociedad global. México. 1999. 2a edición. p. 58.
} 
concepción ecléctica donde antes que una sociedad deberíamos pensar más bien en un espacio de cooperación entre sujetos de muy diferente naturaleza: Estados, entidades sub o infraestatales, organismos interestatales, organismos privados, el sujeto individual, etc. Se trataría de un espacio que puede estar socializado en numerosos sectores, pero que en otros no. ${ }^{75}$ No es correcto afirmar que, por el hecho de que algunos Estados hayan logrado una socialización plena en el ámbito interno, debamos negar el carácter social de la denominada sociedad internacional, basados en el argumento de que la misma no se corresponde estrictamente con el modelo que los Estados tienen dentro de sus fronteras. ${ }^{76}$

En última instancia, lo que se cuestiona es la visión de una "sociedad" internacional con su base fundamentalmente asentada sobre las nociones de “identidad" y de "armonía sustantiva”, como la planteada por nuestro Maestro, el profesor Quintín Alfonsín, quien no tuvo en cuenta la idea de cooperación basada en la tolerancia mutua de las diversidades, sin que fuera indispensable reunirlas en un principio superior, idéntico para todos. Si trasladamos el objetivo primordial de nuestra disciplina hacia esta segunda premisa -la de la cooperación antes que la de la identidadentonces es posible acercarnos con mayor fidelidad a lo que hoy se vive: un escenario, más que una sociedad -este último concepto no sería exacto- en el que participan los Estados, pero también los individuos, las organizaciones gubernamentales (OGs), las organizaciones no gubernamentales (ONGs), las instituciones interestatales y, cualquier agrupamiento humano basado o no en la ficción que transita o viva en él. Sería un mundo más próximo al de las obras cinematográficas de Steven Spielberg o de George Lucas, donde pueden observarse no sólo a seres humanos sino también a criaturas en parte humanas y en parte animales; a creaciones de avatares, de seres pensantes totalmente artificiales que le disputan la inteligencia -y muy pronto los sentimientos- a los seres humanos que los han creado; a entidades básicamente humanas "mejoradas"

\footnotetext{
${ }^{75} \mathrm{Si}$ es posible una sociedad internacional con culturas diferentes será una cuestión a investigar en el futuro. Pilar Allegue adelanta que: "la diversidad cultural es un hecho natural, es un valor en el sentido antropológico, pues 'la especie' no se desarrolla bajo el régimen de una monotonía uniforme sino a través de modos extraordinariamente diversificados." Allegue, Pilar. En torno a la soberanía ¿soberanía, antinomia de la diversidad cultural? Boletín de la Facultad de Derecho. España. 1997. No. 12. p. 83 .

${ }^{76}$ Santos Belandro, Ruben. Propuestas metodológicas para la enseñanza del derecho internacional privado en el s. XXI. Monografía mecanografiada. 2006.
} 
con elementos electrónicos incorporados, que les permitan superar su capacidad natural, etc.; cada uno de estos seres provenientes de galaxias diferentes y no de un mismo medio". ${ }^{77}$

Como señala Ibáñez con acierto, "la sociedad internacional contemporánea es una sociedad en crisis, a caballo entre la sociedad internacional de Estados y la sociedad mundial de individuos. Esta sociedad internacional es una sociedad compleja (...). Se encuentra en proceso de mutación, de cambio, o en situación de crisis, como consecuencia de las tensiones dialécticas que se producen entre los nuevo y lo viejo, entre el futuro y el pasado, entre un mundo de Estados que continúa anclado en el viejo dogma de la soberanía nacional, y un mundo complejo, global e interdependiente, en el que no existen fronteras entre las soluciones nacionales y egoístas que continúan ofreciendo los Estados y las soluciones comunes y solidarias que demandan el carácter global y humano de los problemas". De todos modos concluye con una afirmación que compartimos: "denominar sociedad internacional a esas relaciones sociales que desbordan lo interestatal es científicamente problemático". Ante el dilema de optar entre lo viejo ya obsoleto y lo nuevo aún incompleto, el autor se inclina por considerar la existencia de una sociedad post internacional $7^{78}$, que sería "el conjunto de relaciones sociales conformada por las interacciones que se dan en el seno de la sociedad internacional de Estados y entre todos los actores de las relaciones internacionales, gubernamentales o no, públicos y privados, según pautas de comportamiento orientadas a la preservación de objetivos elementales del orden social". ${ }^{79}$

Recoge la idea de Bull de que estamos ante un nuevo medievalismo: un sistema de autoridades solapadas y de lealtades múltiples. ${ }^{80}$ "Los Estados soberanos comparten

\footnotetext{
${ }_{77}^{7 b}$ Ibídem

${ }^{78}$ Considera adecuado el calificativo "post internacional" por cuanto "es posterior en el tiempo a la sociedad internacional de Estados, surge gracias a la existencia previa de la sociedad internacional de Estados, y transmite adecuadamente la idea de cambio en curso e indeterminado, en el sentido de que sugiere el declive de los patrones tradicionales arraigados, sin indicar al mismo tiempo, hacia dónde pueden dirigirse los cambios".

${ }^{79}$ Ibáñez Muñoz, Joseph. Poder y autoridad (...). Op. cit. p. 49 a 52.

80 "En suma, lo que es nuevo en todo esto no es el resurgimiento -y la tolerancia- de las referencias múltiples de lealtad sino la aceptación de derecho de las personas (y de otras entidades, incluyendo corporaciones transnacionales) a componer su propia identidad, construyendo el complejo de referencias de lealtad que mejor manifieste quién ellos quieren ser. En ese sentido, hemos entrado en una era de identidades libremente imaginadas, en la cual la elección personal ya no está circunscrita por accidentes o manipulaciones de genética, clase, lugar u objetivo 'natural': la religión de sus vol.08, nº. 01, Rio de Janeiro, 2015. pp. 299-349 333
} 
hoy el escenario de la política mundial con otros actores del mismo modo que en los tiempos medievales tenía que compartirse el escenario con otras asociaciones (...)". Podríamos pensar que nos encontramos a comienzos del s. XXI con un sistema de autoridades solapadas y fragmentadas, cuyas interacciones serían análogas a las del medievalismo de Europa entre los s. XII a XVI. ${ }^{81}{ }^{82}$

\section{EL INDIVIDUO}

El derecho internacional privado está destinado a regular fundamentalmente el relacionamiento de los sujetos privados, solo o conformando agrupamientos, cuando sus actividades trascienden el ámbito estatal. Si bien ello constituye la parte principal de nuestra ciencia, el tratamiento del individuo y de las actividades que desarrolla se ha realizado en nuestro Derecho de dos maneras:

1. por un lado, concibiendo al sujeto privado como un mero recipiendario de normas ius internacional privatistas, lo cual se realizó desde los primeros momentos en Uruguay; o, por el contrario, como actor en la arena jurídica, habilitado para intervenir en la selección y/o en la creación de normas, y en la dilucidación de sus litigios que originen sus relaciones;

padres, su lugar de nacimiento, su casta profesional o social. Pero no necesitan hacer eso: crecientemente, por el Derecho nacional y por el uso internacional están siendo liberados para diseñar sus propias identidades. Es una responsabilidad inmensa, la libertad última, y una reconfiguración promisoria de las dinámicas internas del sistema internacional”. Franck, Thomas M. Clan, and superclan: loyalty, identity and community in law and practice. American Society of International Law. American Journal of International Law. 1996. 3. p. 365. Ver también: Benyekhlef, Karim. L'Internet: un reflet de la concurrente des souverainetés. Lex Electronica. Vol. 8. No. 1. Automme/Fall 2002.

${ }^{81}$ Retomando también a Bull, Ibáñez señala que "Son cinco las características que indican una tendencia hacia el nuevo medievalismo: la integración regional entre Estados, la desintegración de los Estados como consecuencia de reclamaciones autonomistas e independentistas de entidades subestatales, la reaparición de la violencia internacional privada que cuestiona el monopolio estatal sobre la violencia legítima, el protagonismo creciente de las organizaciones transnacionales empresas multinacionales, movimientos políticos, organizaciones no gubernamentales, movimientos religiosos y algunas organizaciones internacionales- y la unificación tecnológica del mundo a través de los medios de comunicación y de transporte. Ibáñez Muñoz, Joseph. Poder y autoridad (...) Op. cit. p. 54 .

${ }^{82}$ En base a lo dicho, Ianni define a la sociedad global, como "una sociedad compuesta por naciones y nacionalidades, etnias y clases sociales, empresas transnacionales y organizaciones multilaterales, estructuras de poder nacionales y estructuras de poder supranacionales, geopolíticas continentales y mundiales, industrias culturales nacionales e internacionales, ideas nacionalistas y aun colonialistas, al lado de ideas internacionalistas o propiamente cosmopolitas, formas de participación de individuos, grupos, clases y colectividades en la máquina del mundo que nos permiten imaginar al ciudadano del mundo". Ianni, Octavio. La sociedad global. Op. cit. p. 119. 
2. por el otro, otorgándole a partir de la sanción de la Ley General, un mayor realce al respeto de los derechos humanos fundamentales, reconociéndolos explícitamente -por lo menos en la letra- puesto que descontamos que el respeto de estos derechos fundamentales conforma ya, una parte esencial del orden público internacional de nuestro país, en cuanto vivimos en un Estado republicano de Derecho. Veamos entonces, la evolución producida en los dos sectores. $^{83}$

El individuo: ¿sujeto pasivo o sujeto activo en el derecho internacional privado?

Hasta aproximadamente el año 1975 -fecha en la que comienzan a aprobarse las Convenciones de las C.I.D.I.P.s- en el ordenamiento jurídico de Uruguay el individuo resultó totalmente objetivado por el Derecho, en cuanto se le había impuesto un férreo sistema de conflicto preceptivo, que sólo le permitía a sus destinatarios obedecer. Las razones ya fueron dichas: que el derecho internacional privado era considerado un Derecho que resolvía un conflicto de soberanías entre Estados -un ius supra iura en estado de máxima pureza- y que en la tarea de solución de tales conflictos los individuos no tenían las aptitudes indispensables para realizar algún aporte. ${ }^{84}$

Más próximo en el tiempo se argumentó que como éramos países en vías de desarrollo, podíamos quedar expuestos in natura a las imposiciones de la parte fuerte, ubicada por lo general en los países altamente industrializados -en especial respecto del área de los contratos- quien podía imponer con facilidad su ley y sus jueces. ${ }^{85}$ Este último argumento no tenía en cuenta que la adopción de tal postura -además de ser profundamente antidemocrática- conduce los sujetos privados que viven en los países en vías de desarrollo, igualmente a un subdesarrollo mental, transformándolos en seres

\footnotetext{
${ }^{83}$ Hacemos la salvedad de que estos razonamientos hacen referencia en forma predominante al Derecho occidental, puesto que "las nociones de 'individuo' o de 'sociedad", que constituyen los fundamentos mismos de nuestras ciencias sociales, no se encuentran forzosamente en otras culturas. Muchas de las culturas no ven una línea de fractura entre lo humano, lo cósmico y lo divino; entre la naturaleza y la cultura; entre los humanos, los animales y las plantas; entre el pasado y el futuro; entre los vivos y los muertos; entre los mundos visibles e invisibles. ...) El pluralismo, basado ciertamente sobre la percepción de la pluralidad, incluye además una convicción de que cualquiera se el grado de realidad que nuestras ideas puedan tener, ellas no son toda la realidad." Eberhard, Christoph. Le droit au miroir des cultures. Pour une autre mondialisation. Paris. 2010. p. 38.

${ }^{84}$ Vargas Guillemette, Álvaro. Criterios de solución de los llamados conflictos de leyes en su relación con los Tratados de Montevideo de 1889. Montevideo, octubre de 1938. Ibídem. Informe producido por el Dr. Álvaro Vargas Guillemette sobre el Tratado de Derecho Civil Internacional. Montevideo. 1940. Ibídem. Codificación nacional de derecho internacional privado. Montevideo. 1943.

${ }^{85}$ Fresnedo, Cecilia. La autonomía de la voluntad en la contratación internacional. Montevideo. 1991. vol.08, nº. 01, Rio de Janeiro, 2015. pp. 299-349 335
} 
dependientes, pasivos, donde la creatividad jurídica de que podían gozar, era considerada una mala palabra. Tampoco se prestaba atención a que las soluciones que podían aportar los sistemas jurídicos en la materia, no necesariamente tenían por qué ser siempre adecuadas al caso concreto, y favorables a sus intereses de los propios particulares. $^{86}$

A pesar de este bloqueo legal muy fuerte -apoyado por sectores selectos de la doctrina nacional- desde el último cuarto del s. XX se fueron aprobando distintas Convenciones internacionales que les fueron adjudicando paulatinamente a los particulares un protagonismo importante, tanto para la determinación de la ley aplicable como del juez competente. Contamos al respecto con la Convención Interamericana sobre Arbitraje Comercial Internacional aprobada en Panamá, en enero de 1975, la cual fue seguida de otras de igual origen; y por Convenciones con un ámbito de aplicación más extenso, como la Convención de Viena sobre compraventa internacional de mercaderías, o la Convención de las Naciones Unidas sobre reconocimiento y ejecución de las sentencias y laudos arbitrales extranjeros de 1958.

La ratificación de estos Tratados chocaba evidentemente -y a la vez erosionabael art. 2403 del Código Civil, el cual seguía afirmando con (aparente) contundencia que

Las reglas de competencia legislativa y judicial determinadas en este Título no puede pueden ser modificadas por la voluntad de las partes. Ésta sólo podrá actuar dentro del margen que le confiere la ley competente.

A partir del año 1975 entonces, hay un cambio en el tratamiento a darle a los sujetos privados. En lugar de objetos del Derecho, a cuyas normas sólo cabía obedecer, paulatinamente se los va considerando sujetos de derecho o más bien actores, cuya intervención se volvía indispensable para solucionar tanto sus conflictos de intereses, como los conflictos normativos y los jurisdiccionales sobre el plano internacional. A tal punto llegó este cambio alentado por las Convenciones internacionales, que como en el

\footnotetext{
${ }^{86}$ Una piedra en el zapato de esta concepción monolítica estaba representada por el art. 5 del Protocolo Adicional a los Tratados de Montevideo de 1940, ratificado por Argentina, Paraguay y Uruguay, donde se estableció que: "la jurisdicción y la ley aplicable según los respectivos Tratados, no pueden ser modificadas por voluntad de las partes, salvo en la medida en que lo autorice dicha ley", pero la doctrina nacional minimizó su alcance y durante mucho tiempo asimiló su inteligencia, erróneamente, al art. 2403 del Código Civil de Uruguay.
} 
caso de la Convención de Viena mencionada -norma de jerarquía superior- las partes podían si lo deseaban, dejar de lado las soluciones que ella misma había adoptado.

Esta exasperante situación, donde las normas convencionales decían una cosa diferente de las normas legales, creó una fuerte fricción entre ambos cuerpos normativos, situación que hubo que solucionar de la única manera posible: reconociéndole a los sujetos privados el derecho fundamental a la libertad de elección de normas o de jueces estatales, o de creación normativa y de selección de magistrados privados, derecho a la libertad reconocido por la Constitución de la República. Con las limitaciones -por supuesto- que pudieran caber en el caso específico, en beneficio del interés general o de la parte débil del contrato. La pirámide debía ser invertida: partiendo de la proscripción absoluta de antaño -dotada de algunas excepciones- debía arribarse a la libertad como principio de hogaño, con algunas exclusiones basadas en el interés general. Este cambio de eje recién se logra con la aprobación de la Ley General de Derecho Internacional Privado objeto de esta monografía, y que como veremos en Capítulos subsiguientes, en absoluto es de carácter general e irrestricto.

La alusión expresa a los derechos humanos fundamentales

El inciso 2 del art. 5 de la Ley General introdujo una mención expresa a los derechos fundamentales del hombre, la cual no tiene antecedentes en la legislación de derecho internacional privado de Uruguay. Esta referencia se halla ubicada dentro del artículo encargado de regular la excepción de orden público internacional, y para su mayor inteligencia reproducimos íntegramente:

Los tribunales y otras autoridades competentes, mediante decisión fundada, declararán inaplicables los preceptos de la ley extranjera, cuando ellos contraríen en forma grave, concreta y manifiesta, principios fundamentales de orden público internacional en los que la República asienta su individualidad jurídica.

Entre otras, esta situación tendrá lugar cuando la aplicación del Derecho extranjero resulte inconciliable con los derechos fundamentales consagrados en la Constitución y en las Convenciones internacionales de las que la República sea Parte.

Ha sido un tema debatido en nuestra doctrina determinar si el examen de la aplicación de los derechos fundamentales debe realizarse antes del funcionamiento de 
la regla de conflicto ${ }^{87}$; o luego que ésta ha funcionado, como un aspecto a incluir dentro de la excepción del orden público internacional. En otra oportunidad hemos defendido la última posición como la más aconsejable en principio ${ }^{88}$, la cual coincide con la sustentada por la Ley General al tenor de la lectura del art. 5. Sin perjuicio de lo ya expresado, el momento parece oportuno para explayarnos más ampliamente sobre esta importante cuestión.

Dentro de nuestro ordenamiento jurídico entonces, en principio no es posible aplicar los derechos del hombre en forma anticipada al funcionamiento de la regla de conflicto de leyes o de jurisdicciones, como un ius cogens que no admite modulaciones, restricciones, y en definitiva un afinamiento a llevar a cabo ante la presencia del caso concreto. Debemos por tanto, hacer funcionar la regla indirecta, y luego examinar si la solución material a la que se ha arribado ataca o no estos derechos fundamentales. Las razones que abundan en apoyo a esta posición son variadas y han sido ampliamente examinadas por la Profesora Mireille Delmas-Marty en su obra Les forces imaginantes du droit. Le relatif et l'universel (París. 2004). ${ }^{89}$

En primer término, acertadamente considera que respecto del debate sobre el universalismo de los derechos del hombre, cabe mencionar el enfrentamiento entre los diversos instrumentos regionales (individualismo de las Convenciones europea y americana; opuesta al comunitarismo de la Carta Africana de los Derechos del Hombre "y de los pueblos"; la Declaración de Bangkok sobre los "valores asiáticos"; o el teocratismo de la Carta Árabe y la Declaración Islámica), lo cual más allá de los

\footnotetext{
${ }^{87}$ Fresnedo, Cecilia. El régimen internacional de la filiación y los derechos humanos: un diálogo de las fuentes. Revista de Derecho de la Universidad Católica del Uruguay. p. 185.

${ }^{88}$ Santos Belandro, Ruben. Derecho Civil Internacional y de Familia. Montevideo. 20o9. p. 216 y 49.

${ }^{89}$ Ante la pregunta que ella misma se formulaba respecto de si una comunidad de Derecho a nivel internacional puede crear una comunidad de valores, se respondía que "antes de arriesgar una respuesta, vale mejor medir las dificultades que pueden presentar conflictos potenciales entre los valores que subyacen en los conceptos jurídicos de vocación universal: conflictos en el seno de los derechos del hombre, e igualmente conflictos 'mixtos' entre el hombre y su o sus comunidades de pertenencia y la Humanidad convertida en categoría jurídica distinta (víctima de crímenes o titular de un patrimonio); o más ampliamente aún, entre las personas y las cosas, el hombre y el mercado, como se ha visto a propósito de los bienes públicos mundiales, entre el mercado y la Humanidad". p. 123 .
} 
documentos en sí, está revelando una falta de visión homogénea de los derechos, en cuanto éstos últimos se encuentran atravesados por múltiples tensiones..$^{90}$

En segundo lugar, parece de sentido común, tomar en cuenta el desdoblamiento de los instrumentos jurídicos de protección de los derechos del hombre entre derechos civiles y políticos por un lado, y derechos económicos, sociales y culturales por el otro. Los últimos fueron consagrados en documentos posteriores y en épocas muy diferentes a los primeros.

En tercer lugar, debe distinguirse entre libertades (derecho del) y créditos (derechos a); entre el poder de exigir un derecho de crédito ante el Estado, que se yuxtapone al poder de actuar, base de las libertades tradicionales. Se tratará de precisar en el caso bajo estudio, si la relación entre estas dos categorías puede ser de contradicción y/o de complementariedad; sin perjuicio de examinar también, las posibles contradicciones entre derechos integrantes de una misma categoría. ${ }^{91}$

En cuarto término la autora sostiene que los conflictos entre los derechos de una misma categoría se resuelven reconociendo una doble limitación a la aplicación de cada uno: debe tratarse siempre de asegurar el reconocimiento y respeto de los derechos del otro, y deben satisfacerse las justas exigencias de la moral, del orden público y del bienestar general en una sociedad democrática. $\mathrm{Y}$ en cuanto a la jerarquización de los derechos, considera que la mayor parte de los derechos están dotados de lo que ha

\footnotetext{
${ }^{90}$ Op. cit. p. 124. Christoph Eberhard acota que "es un mal método preguntarse si culturas que no comparten la misma matriz cultural conocen o no la noción de los derechos del hombre. Debemos más bien interrogarnos lo que juega en la cultura india (por ejemplo) como el equivalente funcional, o el equivalente homeomorfo, respecto del papel que tienen los derechos del hombre en la cultura occidental. Esa noción es el dharma, que designa realidades muy diferentes de los derechos del hombre, puesto que reenvía entre otras, al orden cósmico y que, partiendo del dharma probablemente es la religión la que aparecería como el equivalente homeomorfo en la cultura occidental. Para llevar esa clase de enfoque al ámbito del Derecho debemos comenzar por definir a este último de manera más amplia de lo que habitualmente hacemos. Al ejemplo de Michel Alliot (1983), debemos emancipar su definición de la referencia al Estado, a la Razón, a la existencia de normas generales e impersonales, abstraídas de otras realidades sociales. Debe proponer una definición funcional que permita descubrir el 'fenómeno jurídico' en su originalidad en la diversidad de las sociedades. Esos recorridos por la 'alteridad" pueden permitirnos luego, comprender mejor a través de una lógica aditiva de la 'juridicidad' o el Derecho con una ' $\mathrm{D}$ ' mayúscula, donde el derecho con una 'd' minúscula, el etático y moderno, es sólo un aspecto." Le droit au miroir des cultures. Pour une autre mondialisation. Paris. 2010. p. 30."

${ }^{91}$ Delmas-Marty afirma que "conviene matizar las afirmaciones, por un lado existe (a pesar del postulado de homogeneidad) conflictos entre derechos que derivan de un mismo instrumento; y por el otro, el desdoblamiento (a pesar de las contradicciones que presente) que no estaría necesariamente traduciendo un conflicto insuperable". Op. cit. p.125. 
denominado una cláusula escapatoria, que comprende tres tipos de limitaciones: derogaciones, excepciones y restricciones.

En base a lo cual, los derechos fundamentales pueden calificarse en:

- derechos de protección absoluta, que son aquellos sobre los cuales no se admiten excepciones permanentes, ni derogaciones temporales, como por ejemplo: la prohibición de la tortura o de penas o tratamientos inhumanos o degradantes, así como la interdicción de la esclavitud o de las expulsiones colectivas. El valor jurídico a la protección jurídica así expresado, se lee como el respeto a la dignidad humana, en el sentido más fuerte del término. Lo irreductible humano se traduce bajo el término jurídico "inderogable".

1. Una protección cuasi absoluta corresponde a aquellos derechos que pueden ser suspendidos temporalmente en caso de guerra o de otras circunstancias excepcionales, pero fuera de estas circunstancias son protegidos sin excepciones ni restricciones. Delmas-Marty da como ejemplos, el derecho a la no discriminación, la presunción de inocencia y, más ampliamente, los derechosgarantía (el acceso a la justicia y a un proceso equitativo);

2. Una protección relativa corresponde a los demás derechos no incluidos en las categorías anteriores: habrá en ellos una protección relativamente más fuerte para los derechos dotados de cláusulas que prevén excepciones enumeradas limitativamente (el derecho a la vida y el derecho a la libertad de circulación); y una protección relativamente más débil, tratándose de derechos sobre los cuales se admiten restricciones de una forma no limitativa y con un margen nacional de apreciación.

La breve exposición realizada nos permite concluir que el tratamiento a dispensar a los derechos fundamentales del hombre no parece, ni tan homogéneo, ni tan claro. Por lo cual debemos juzgar como adecuada la solución consagrada en el inciso 2 del art. 5 de la Ley General, al incluir el referido tratamiento como una consideración a ser tomada en cuenta, en principio, ex post, luego de que la regla indirecta ha cumplido todas sus etapas y designado el Derecho material aplicable. Sólo el ataque a valores extremadamente importantes ameritaría el recurso al art. 6.

Por otro lado, examinando el problema desde el conflicto de leyes, "el razonamiento de derecho internacional privado parece situarse a otro nivel. La regla de 
conflicto en principio no designa una ley en función de su tenor, más o menos protector de los derechos del hombre, más o menos favorable al interesado, sino que lo hace en función de su conexión con la situación. La conexión por la nacionalidad (por ejemplo) traduce simplemente la convicción de que en materia de estatuto personal, la ley nacional de los interesados mantiene un vínculo estrecho con los problemas presentados. Es siempre deseable intervenir en el caso concreto en un segundo tiempo, y únicamente en un segundo tiempo, en cuanto a los derechos del hombre y al Derecho comunitario. (...) En el primer estadio del razonamiento el fin sería únicamente identificar una conexión que corresponda al centro de gravedad de la situación (...) (lo cual) asegura una coincidencia entre el tratamiento jurídico y el medio sociológico de las personas involucradas, garantizando así una armonía entre el estatuto jurídico de los interesados, y los usos y costumbres del país en el cual están integrados. (...) Permite además a los individuos, conocer por adelantado la ley que sería aplicada a su estado". ${ }^{22}$ ¿Qué se pierde haciendo funcionar la regla de conflicto de leyes y constatar luego, si la solución dictada al amparo de la ley seleccionada ofende o choca gravemente los derechos fundamentales? Absolutamente nada. Por tal motivo, a nuestro modo de ver debemos mantener la postura de privilegiar en lo posible, la actuación en este tema, del orden público internacional a posteriori y no a priori. 9394

\footnotetext{
92 "El razonamiento conflictualista, como vector de la coordinación de los sistemas y de la armonía internacional de las soluciones, sufre el imperialismo y el materialismo del Derecho comunitario y de los derechos del hombre, donde el objetivo no es ya la localización más equilibrada posible de la situación sino la garantía más efectiva posible de los valores de libertad y de igualdad". Hunter-Henin cree poder resolver la contradicción entras las dos lógicas, entre esos dos valores en tensión, adoptando una conexión más territorial del estatuto personal que el de la nacionalidad, ante lo cual el respeto de los derechos fundamentales se vería facilitado. "El ideal sería integrar los derechos fundamentales a la residencia habitual como medio de integración, dotando a la regla de bilateralidad. Así, un individuo casado, de nacionalidad marroquí y con residencia habitual en el sentido de medio de integración en Francia, no podría contraer un segundo matrimonio en su país de origen con una segunda mujer de estatuto personal musulmán. Sería de aplicación la ley francesa como medio de integración, la cual debe conformarse a los derechos fundamentales.". Hunter-Henin, Myriam. Droits des personnes et droits de l'homme: combination ou confrontation? Revue Critique de Droit International Privé. 2006. 95. 4. p. 758 y 774.

${ }^{93}$ En tal sentido ver: Mayer, Pierre. La Convention européenne des droits de l'homme et l'application des normes étrangères. Revue Critique de Droit International Privé. 1991. 80. 4. p.651-665. "Nada permite pensar que concluyendo la Convención (europea) y adhiriéndose a ella, los Estados Partes hayan querido trastocar el funcionamiento de sus sistemas de derecho internacional privado. (...) Sería deseable que el control sea lo suficientemente flexible para que cada Estado conserve el dominio de sus reglas de conflicto de leyes y de jurisdicciones. Los Estados Parte (en la Convención europea) no han confiado a la Corte de Estrasburgo la tarea de unificar las reglas europeas relativas al problema del efecto atenuado del orden público. (...) Debemos permitir a los Estados modular en una vol.08, nº. 01, Rio de Janeiro, 2015. pp. 299-349 341
} 


\title{
LA OPACIDAD DEL INDIVIDUO EN DETERMINADOS ENTORNOS
}

\author{
A la vez de habilitar la consideración de los sujetos individuales como centro de
} la preocupación del derecho internacional privado y su rol activo en la elaboración normativa, en correlación también con el realce de sus derechos fundamentales, lo cual conduce a pensarlo como un fin en sí mismo y no como un medio al servicio de un fin, de acuerdo a la filosofía kantiana; podemos observar una situación inversa: el despliegue de la opacidad del individuo en el mundo cibernético. Como acertadamente lo manifiestan Bermúdez y Martínez, "las nuevas formas de sociabilidad que se desarrollan en este locus, revolucionan las formas tradicionales de comunicarse cara a

cierta medida, la intensidad de su reacción en función del grado de particularismo que él estima bueno tolerar en el seno de su población recientemente inmigrada".

${ }^{94}$ Marie-Claude Najm expone la percepción específica que de los derechos fundamentales tienen los países musulmanes, específicamente sobre la libertad de conciencia y el interés del menor. En cuanto a la libertad de conciencia, si bien la Constitución libanesa, por ejemplo, proclama en el art. q que la libertad de conciencia es absoluta, en El Líbano el individuo debe pertenecer obligatoriamente a una comunidad determinada. Si bien puede salir de su religión, no importa cual, ello será para ingresar a otra, pues un libanés sin religión es un libanés sin estatuto civil o político. Sólo indirectamente, a través del reconocimiento acordado a su comunidad es que el individuo puede ejercer su libertad de conciencia. Precisamente se halla allí el origen del sistema comunitario, que en el sendo de un Estado teocrático tiene por objetivo preservar la autonomía de las comunidades. Respecto al interés superior del menor, ese interés es examinado de la misma manera en los diversos sistemas jurídicos. En un sistema confesional como en El Líbano, la identidad de religión del adoptado y del adoptante es una condición esencial de la adopción. Un juicio francés de adopción de un niño libanés católico por una pareja de franceses no será reconocido en El Líbano si los adoptantes no son católicos. El interés del menor, derecho fundamental si lo es, no es percibido de la misma manera en los sistemas laicos y en los sistemas confesionales, especialmente en Derecho musulmán, donde la educación del niño en la fe musulmana y en un medio musulmán es juzgado fundamental. Esas observaciones, señala Najm, conducen a la siguiente constatación: los derechos fundamentales están situados culturalmente y socialmente. La "cultura universal" de los derechos del hombre se choca ante una realidad concreta innegable: la falta de universalidad de esos derechos. Las considerables divergencias en la recepción y en la comprensión de los derechos fundamentales en los diversos sistemas jurídicos repercuten sobre el derecho internacional privado, especialmente a través de la excepción de orden público. En El Líbano, los derechos fundamentales de los individuos se hallan pues alterados, y a veces neutralizados, por la dimensión religiosa del estatuto personal. (...) El respeto de los derechos fundamentales se choca con el respeto a los mismos sistemas confesionales. (...) La heterogeneidad del Derecho interno de la familia en El Líbano impide desprender una visión común de los derechos fundamentales. En presencia de estatutos a menudo antinómicos, tomar posición a favor de una determinada concepción es necesariamente tomar partido por una y descartar la otra. Basta citar el ejemplo del matrimonio: indisoluble para los cristianos católicos; disoluble para los cristianos ortodoxos mediante divorcio judicial y bajo ciertas condiciones; por mutuo consentimiento para los drusos; y repudiación unilateral para los judíos y los musulmanes. Las comunidades libanesas tienen una dimensión religiosa y, a través de ella: jurídica, política y social. ¿Debemos sorprendernos si a causa de este pluralismo confesional ningún derecho fundamental propio de la familia figure en la Constitución libanesa? Najm, Marie-Claude. Le droit internacional privé libanais, entre la réception des droits fondamentaux et les exigences du système communautaire. 
cara, de encontrarse físicamente en el lugar y de interactuar simbólicamente. Quienes se comunican son seres digitales. El cuerpo no precisa permanecer en el lugar donde antes lo necesitaba para la interacción, es amputado por el texto y/o el correo electrónico, por lo que la sincronización para el encuentro cara a cara se torna inútil. Desaparecen estigmas asociados a los hombres: raza, género, edad, aspectos difíciles de ocultar en la vida cotidiana". El individuo pierde todos los aspectos de la corporeidad y la situación lo alienta para crear una individualidad imaginada. ${ }^{95}$

\section{LA MULTIPLICIDAD DE LAS LEALTADES}

Hemos citado -y es conveniente volverlo a mencionar- que las personas asumen múltiples lealtades. Como algunos autores señalan, este problema no es nuevo, pero cuando ocurría en el pasado se trataba de una lealtad impuesta, en cambio hoy se ha convertido en una cuestión de elección personal, acaso por primera vez en la historia humana. Las personas reclaman el derecho a crear sus propias identidades, el derecho a configurar motu proprio aquellas referencias de lealtad que mejor manifiesten quiénes ellos quieren ser: "hemos entrado en una era de identidades libremente imaginadas", los individuos "están siendo liberados para diseñar sus propias identidades". ${ }^{96}$ También aquí nos encontramos ante un panorama complejo que debe ser analizado como tal. Ha sido pacíficamente aceptado que los puntos de conexión "domicilio" y "nacionalidad" intentan traducir un vínculo firme entre un Estado y sus súbditos, se basa en un supuesto deber de fidelidad lo que genera la obligación de aplicar las normas propias de su entorno o de sus raíces a todo aquello que se refiere a su vida personal y a la de su

\footnotetext{
95 "Las interacciones socio-culturales se desenvuelven en un nuevo espacio caracterizado por la desterritorialización y la inmaterialidad, dando lugar a una dimensión experiencial novedosa, dominada por el 'como si' y donde los individuos son liberados de toda carga de identidad interpeladora y exigidos únicamente de interacciones con informaciones o textos." Bermúdez, Emilia y Martínez, Gildardo. Los estudios culturales en la era del ciberespacio. Conferencia. Setiembrediciembre. Año 8. No. 26. UNAM. Facultad de Ciencias Políticas y Administración Pública. Toluca. México. p. 14. Se agrega que: "desde ese punto de vista, el ciudadano virtual estaría en las antípodas del sujeto político universalista de la modernidad. La acción ciudadana virtual se ejercería pues, alrededor de intereses puntuales, favoreciendo movilizaciones espontáneas tan fácilmente constituidas como disueltas, como lo había identificado ya André Lemos hace 10 años hablando de 'inclusiones efímeras' basadas sobre intereses puntuales y comunes, más que de una exclusividad comprometida." Goupil, Sylvie. Médiatisation de l'espace public et nouvelles technologies de l'information et de la communications: vers le citoyen virtual? Colloque de la Société Québécoise de Science Politique. Montréal. 26-28 mai, 2004.

${ }^{96}$ Franck, Thomas M. Clan and superclan (...) Op. cit.
} 
familia. El concepto de domicilio en la actualidad se ha transmutado en direcciones electrónicas, que no siempre coinciden con el origen geográfico que exhiben. Pero además de este mundo cibernético, existen otros agrupamientos que generan una lealtad tan fuerte como la del Estado, ante lo cual esas lealtades, fidelidades o adhesiones deben ser tenidas en cuenta por el Derecho.

Estas peculiaridades que hemos puesto en relieve en otras ocasiones ${ }^{97}$ ha sido prácticamente compartida por la doctrina más avanzada. "Una liberalización progresiva de las sujeciones legales se halla en marcha: poco a poco el nombre, el sexo y, de un modo general, el cuerpo, y sin duda la pareja y la filiación, devienen un lugar de autodeterminación de sí mismo que soporta pocas trabas, fuera del respeto a la libertad del otro. Ningún Derecho común de las personas y de la familia se desprende de esta evolución. Lo múltiple y la singularidad prevalecen: varios sexos sucesiva o simultáneamente, varios nombres, varios modelos de pareja con numerosas pasarelas, los individuos se benefician ya de un Derecho de las personas y de la familia à la carte"..$^{8}$

\title{
THE ACTORS OF THE PRIVATE INTERNATIONAL LAW OF THE 2IST CENTURY
}

\begin{abstract}
The phenomenon of globalization has seriously disrupted the image of traditional private international law based on the ideas of distribution, location, territory and sovereignty of States, all issues that attempted to do one appropriate treatment in the end of the nineteenth century and the middle of twenty century. Today national frontiers - the basis for reasoning of a private international law on premises savignianas - are often inconsiderables. The human being has become ubiquitous, in the sense that
\end{abstract}

\footnotetext{
97 Santos Belandro, Ruben. La ley No. 18.620 sobre identidad de género y el orden público internacional. Revista Uruguaya de Derecho de Familia. Montevideo. 2010. 22. p. 219. Ibídem. Acreditación internacional de las uniones de hecho a la luz de la ley No. 18.246 de 18 de diciembre de 2007. Montevideo. 2008. Ibídem. Minoridad y ancianidad en el mundo actual. Un estudio desde el derecho internacional privado comparado. El testamento vital. Montevideo. 2007.

98 "El concepto de estado de las personas no es ya más, un concepto federador susceptible de servir de base al estatuto personal. En el seno de este concepto coexisten una multiplicidad de estatutos, según los intereses juzgados prioritarios. El individuo no es tratado ya más en función de su cualidad de persona sino en función del lugar -intercambiable- que ocupa en una determinada relación". Hunter-Henin, Myriam. Droits des personnes (...). Op. cit. p. 745 y 746.
} 
his thought, will and action, can overcome the region where he was born and lives, to influence anywhere in the world, agreeing eg contracts electronically. It is unavoidable to consider these circumstances to save the risk of promoting an inadequate or ineffective law.

Corresponds then to revisit the old criteria on which is based our discipline. It is conceivable that in some important areas transformation undergone by the State has been no longer the focus of international society. It is also necessary to reason about the fact that they have also transformed the patterns of power in international relations, as to its nature and as to the ways of operating in the new model of society. The power and authority remain central themes in our area, but vary the actors. New ways of managing certain issues, that globalization has led to the whole world.

For better treatment, we divide the topic into three parts: the first will allow us to observe the evolution who have experienced the States in their structure and the person managing; the second will be devoted to clarify the concept and characteristics of international society as its presented today; and last, be referred to the individual, reference center of private international law. In Section 2, we examine the methodological variety present in the private international law. In Section 3 we will find that the problem is not methodological pluralism but in finding proper coordination between different legal systems. Coordination can and should be realized on the regulatory, institutional and procedural level, using a large variety of tools.

Keywords: Globalization, Private International Law, State Transformation, International Society, Individual.

\section{BIBLIOGRAFÍA}

ALFONSÍN, Quintín. El orden público. Montevideo. 1938.

ALLEGUE, Pilar. En torno a la soberania: ¿soberanía, antinomia de la diversidad cultural? Boletín de la Facultad de Derecho. España. 1997. No. 12.

ARTEAGA Nava, Elisur. El poder. Algunas consideraciones. Boletín de la Facultad de Derecho. España. No.14 (1999).

BARILE, Giuseppe. La fonction historique du droit International privé. Recueil des Cours. 1965 .

BAUMAN, Zygmunt. La globalización. Consecuencias humanas. Argentina. 2005. La sociedad sitiada. Argentina. 2004.

BENAYOUN, Maurice. Un monde trop humain. Paris. Julio. 1999.

BENYEKHLEF, Karim. L'Internet: un reflet de la concurrente des souverainetés. Lex Electronica. Vol. 8. No. 1. Automme/Fall 2002. 
BENYEKHLEF, Seffar y Karim. Commerce électronique et normativités alternatives. University of Ottawa. Law \& Technology Journal. 2006.

BERTHOU, Renaud. Internet et le respect des principes essentiels du droit du for. Juin. 1999.

Le droit au gré d'Internet: à propos d'une réseautisation fort peu anodine de l'univers juridique. Lex Electronica. Vol. 11. Printemps/Spring. 2006.

BLANCO y ROMERO, Asunción, y Cánoves Valiente, Gemma. Tecnologías de la información y multifuncionalidad del territorio. asunción.blanco@uab.es

BOBBIO, Norberto. Estado, Gobierno y Sociedad. México. 1991.

CAMMARATA, Manlio. Queli leggi per il "territorio Internet"? Interlex. 19 de junio de 1997.

CAPELLA, Juan Ramón. Fruta prohibida. Una aproximación histórico-teorética al estudio del Derecho y del Estado. 3ª. Edición. Madrid. 2001.

CARBONNIER, Jean. Flexible Droit. Textes pour une sociologie du droit sans rigueur. Paris. 1983.

CARRILLO Salcedo, Juan-Antonio. Droit international et souveraineté des États. Cours general de droit international public. Recueil des Cours. 1996.

CRISTOS, Velasco San Martín. A propósito de la jurisprudencia y el derecho aplicable en Internet. UNAM. Noviembre de 2005.

DE JOUVENEL, Bertrand. The pure theory of politics. Liberty Fund. 1963.

DE PRADA GARCÍA, Aurelio. Pirámides y redes: el concepto de Derecho. Boletín de la Facultad de Derecho. España. 1999.

DEFFAINS, Bruno y Fenoglio, Philippe. Économie et ordre juridique de l'espace virtuel. Revue Économique. Vol. 52. Numéro hors série. Octobre. 2001.

DELGADO-OCANDO, J. M. Hacia una comprensión posmoderna del derecho. Dikaiosyne. Venezuela. No. 1. p. 24.

DEPREZ, Jean. Droit international privé et conflits de civilisations. Aspects méthodologiques. Les relations entre systèmes d'Europe Occidentale et systèmes islamiques en matière de statut personnel. Recueil des Cours. 1988.

DUPUY, René-Jean. Communauté international et disparité de développement. Recueil des Cours de l'Académie de La Haye. 1979. 
EBERHARD, Christoph. Le droit au miroir des cultures. Pour une autre mondialisation. Paris. 2010.

FARÍA, José Eduardo. El Derecho en la economía globalizada. Madrid. 2000.

FRANCESCAKIS, Phocion. Introduction à l'édition française a la obra de Santi Romano: L'ordre juridique. Paris. 1975.

FRANCK, Thomas M. Clan, and superclan: loyalty, identity and community in law and practice. American Society of International Law. American Journal of International Law. 1996.

FRESNEDO, Cecilia. El régimen internacional de la filiación y los derechos humanos: un diálogo de las fuentes. Revista de Derecho de la Universidad Católica del Uruguay.

La autonomía de la voluntad en la contratación internacional. Montevideo. 1991.

GILLET, Alexandre. Derives atopiques. Le "non lieu” ou errantes d'un concept. http//espaces.temps.revues.org/document. 1975.html.

GOUPIL, Sylvie. Médiatisation de l'espace public et nouvelles technologies de l'information et de la communications: vers le citoyen virtual? Colloque de la Société Québécoise de Science Politique. Montréal. 26-28 mai, 2004.

GUTZWILLER, Max. Le développement historique du droit International privé. Recueil des Cours. 1929.

HUNTER-HENIN, Myriam. Droits des personnes et droits de l'homme: combination ou confrontation? Revue Critique de Droit International Privé. 2006.

IANNI, Octavio. La sociedad global. 2ª edición. México. 1999.

IBÁÑEZ MUÑOZ, Joseph. Poder y autoridad en las relaciones internacionales: el control del comercio electrónico en Internet. Universitat Pompeu Fabra. Barcelona. 2002.

JUENGER, Friedrich, K. General Course of Private International Law. Recueil des Cours. 1985 .

Krabbe, H. L’idée moderne de l'État. Recueil des Cours. 1926.

LAVENUE, Jean-Jacques. Souveraineté, territoires, espaces, espace virtuel. Cours Commun du Master "Activités transnationales". 2003-2004.

Lavenue, Jean-Jacques. TIC, souveraineté et ordre public. Http://www2.univlille2.fr/droit(enseignants/lavenue; 
Internationalisation ou américanisation du droit public: l'exemple paradoxal du droit du cyberespace confronté à la notion d'ordre public. Lex Electronica. Vol. 11. No. 2. (Automme/Fall 2006).

LESSIG, Lawrence. Las leyes del ciberespacio. Cuadernos Ciberespacio y Sociedad. No. 3. Marzo, 1999.

LOQUIN, Éric. Les regles matérielles internacionales. Recueil des Cours. 2006.

MARTÍNEZ, Gildardo. Representaciones, discursos y prácticas de actores en torno al ciberespacio. Ponencia presentada en el XXIII Congreso de la Asociación de Estudios Latinoamericanos. Washington D.C. Septiembre 6-8, 2001.

MAYER, Pierre. La Convention européenne des droits de l'homme et l'application des normes étrangères. Revue Critique de Droit International Privé. 1991.

MEIJERS, E. M. L'histoire des principes fondamentaux du droit International privé à partir du moyen âge. Recueil des Cours. 1934.

MENTHE, Darrel. Jurisdiction in cyberspace. A theory of international spaces. Michigan Telecomm. Tech. Law Review. 69. 1998.

MESSNER, Dirk. La sociedad de redes. 1995.

NAJM, Marie-Claude. Le droit internacional privé libanais, entre la réception des droits fondamentaux et les exigences du système communautaire.

PARISIEN, Serge. Un essai sur le mode de formation des normes dans le commerce électronique.

PECES-BARBA MARTÍNEZ, G. Introducción a la Filosofía del Derecho. Madrid. 1983.

PONTIER, Jean-Marie. La problématique du territoire et du droit. Droit et Complexité. Por une nouvelle intelligence du droit vivant. Rennes. 2007.

QUADRI, Rolando. Droit international cosmique. Recueil des Cours. 1959.

RIGAUX, François. Les situations juridiques individuelles dans un système de relativité générale. Recueil des Cours. 1989.

ROMANO, Santi. L'ordre juridique. Paris. 1975.

SANTOS BELANDRO, Ruben. Acreditación internacional de las uniones de hecho a la luz de la ley No. 18.246 de 18 de diciembre de 2007. Montevideo. 2008.

Derecho Civil Internacional y de Familia. Montevideo. 2009.

Derecho Comercial internacional. Montevideo. 2008. 
La ley No. 18.620 sobre identidad de género y el orden público internacional. Revista Uruguaya de Derecho de Familia. Montevideo. 2010.

La sociedad internacional como fundamento del derecho internacional privado. Direito e Comércio Internacional. Tendências e perspectivas. Estudos em homenagem a Irineu Strenger. São Paulo. 1994.

Las nociones de sociedad internacional y Estado: dos claves para ingresar al derecho internacional privado uruguayo. Avances del Derecho Internacional Privado en América Latina. Liber Amicorum

Jürgen Samtleben. Coordinadores Jan Kleinheisterkamp y Gonzalo A. Lorenzo Idiarte. Montevideo. 2002.

Las normas de aplicación inmediata en la doctrina y el derecho positivo. Revista de la Facultad de Derecho. Julio-Diciembre de 1995. No. 8.

Minoridad y ancianidad en el mundo actual. Un estudio desde el derecho internacional privado comparado. El testamento vital. Montevideo. 2007.

Propuestas metodológicas para la enseñanza del derecho internacional privado en el s. XXI. Monografía mecanografiada. 2006.

SCHOENBORN, W. La nature juridique du territoire. Recueil des Cours. 1929.

SEIDL-HOHENVELDERN, Ignaz. International economic "soft law". Recueil des Cours. 1979.

ZAGREBELSKY, Gustavo. El Derecho dúctil. Ley, Derecho, Justicia. 7ª̣. Edición. Madrid. 2007.

VARGAS GUILLEMETTE, Álvaro. Criterios de solución de los llamados conflictos de leyes en su relación con los Tratados de Montevideo de 1889. Montevideo, octubre de 1938.

WEIL, Prosper. Le droit International en quête de son identité. Cours général de droit international public. Recueil des Cours. 1992.

Trabalho enviado em 17 de dezembro de 2014.

Aceito em 22 de janeiro de 2015. 